\title{
Differential Projections of the Anterior and Posterior Regions of the Medial Amygdaloid Nucleus in the Syrian Hamster
}

\author{
DIANA M. GOMEZ AND SARAH WINANS NEWMAN \\ Department of Anatomy and Cell Biology, Medical Science Building II, \\ University of Michigan, Ann Arbor, Michigan 48109-0616
}

\begin{abstract}
The medial nucleus of the amygdala is important for the neural control of reproductive behavior in the adult male Syrian hamster. Two types of signals are essential for this behavior, chemosensory stimuli and gonadal steroids; these signals appear to be received in different parts of the medial nucleus. The anterior region receives input from olfactory and vomeronasal systems, both of which are required for this behavior, whereas the posterior region receives gonadal hormone inputs. Behavioral studies have also suggested a functional differentiation of these two areas; electrolytic lesions of the anterior, but not the posterior, part eliminates normal sexual behavior. In this study, the efferent projections of the anterior and posterior divisions of the medial nucleus of the amygdala in the Syrian hamster were analyzed throughout the forebrain after injections of the anterograde neuronal tracer, Phaseolus vulgaris-leucoagglutinin. Neurons of the anterior, but not the posterior, medial nucleus, were found to project to numerous olfactory bulb projection areas and to the ventral striatopallidal complex. Within areas of the chemosensory circuitry that control reproductive behavior, the anterior region of the medial nucleus projects to the intermediate part of the posterior bed nucleus of the stria terminalis and the lateral part of the medial preoptic area, whereas the posterior region of the medial nucleus projects to the medial parts of these areas. Differences in targets were also observed in the ventromedial nucleus of the hypothalamus where the anterior region projects to the core while the posterior part projects to the shell of this nucleus. Furthermore, reciprocal projections between the anterior and posterior regions of the medial nucleus were observed. Taken together, these studies support the hypothesis that the anterior and posterior regions of the medial amygdaloid nucleus provide substantially different contributions to the control of reproductive behaviors.
\end{abstract}

Key words: Phaseolus vulgaris-leucoagglutinin, chemosensory pathway, neuronal tract tracing, amygdala

The medial nucleus of the amygdala (Me) is thought to play an essential role in controlling male reproductive behavior and function in the male Syrian hamster ( $\mathrm{Me}$ socricetus auratus). Its location along the chemosensory pathway reflects its importance in integrating and relaying incoming vomeronasal and olfactory stimuli from the accessory and main olfactory bulbs, respectively, to reproductive control areas in the medial telencephalon and diencephalon (Winans et al., ' 82 ). The male Syrian hamster is dependent on both of these chemosensory systems for the control of copulatory behavior (Winans and Powers, '77). Neither system alone controls reproductive behavior, but rather the integration of both types of inputs, presumably within $\mathrm{Me}$, is necessary for normal copulatory behavior to occur. Anatomical evidence suggests that both chemosensory inputs project to the anterior region of $\mathrm{Me}(\mathrm{MeA})$ (Lehman et al., '82), whereas there are no direct olfactory bulb afferents and only sparse vomeronasal inputs to MeP. Previous studies also suggest that the primary efferent pathway of $\mathrm{MeA}$ is the ventral amygdalofugal pathway, whereas the major efferent pathway from posterior $\mathrm{Me}(\mathrm{MeP})$ is the stria terminalis (Lehman and Winans, '83; Kevetter and Winans, '81a). Both of these fiber bundles reach the bed nucleus of the stria terminalis, which is essential for the chemoinvestigatory components of mating behavior (Powers et al., '87). Only the stria terminalis provides direct projections from $\mathrm{Me}$ to the medial preoptic area, a region which controls the execution of copulatory behavior (Lehman and Winans, '83; Powers et al., '87).

\footnotetext{
Accepted September 23, 1991.
} 
In addition to receiving combined chemosensory inputs, $\mathrm{Me}$ is the first nucleus along this pathway with a large population of neurons that actively concentrate gonadal steroids. Androgen-accumulating neurons have been observed primarily in the posterior part of this nucleus (Doherty and Sheridan, '81; Newman et al., '91). Gonadal steroids, like chemosensory signals, are essential for normal reproductive behavior in hamsters and manipulations of gonadal hormone levels have profound effects on neuronal morphology in MeP. Castration in this species results in alterations of the dendritic branching pattern and a decrease in somal area of the neurons, while testosterone treatment prevents these structural changes (Gomez and Newman, '91b). This morphological plasticity in the adult suggests that the connections of this circuitry are being modified by hormones in order to regulate copulatory behavior. In addition to morphological changes, the neurons of MeP display gonadal hormone-mediated changes in neuropeptide levels. Castration in adult rodents results in a decrease in the levels of several different neuropeptides within $\mathrm{Me}$, all of which have been implicated in the control of male rodent mating behavior (Dornan and Malsbury, '89), including substance P (Swann and Newman, '87; Malsbury et al., '87), cholecystokinin (Simerly and Swan- son, '87) and vassopressin (DeVries et al., '85), and testosterone replacement restores the levels of all these substances.

In addition to differences between $\mathrm{MeA}$ and $\mathrm{MeP}$ in the olfactory and vomeronasal inputs, in the primary efferent pathways, in the density of steroid-uptake neurons and in hormonally dependent plasticity, selective lesions of these two areas produce changes in mating behavior of male hamsters that suggest separate functional roles. Bilateral electrolytic lesions of $\mathrm{MeA}$, but not $\mathrm{MeP}$, completely abolish mating behavior (Lehman et al., ' 80 ). In contrast, lesions of $\mathrm{MeP}$ or sectioning of the stria terminalis dismupt only the temporal pattern of copulation (Lehman et al., '83). Thus, the efferents of $\mathrm{MeA}$ in the ventral amygdalofugal pathway would appear to be the essential circuitry for mating behavior to occur. However, damaging the stria terminalis or the ventral amygdalofugal pathway alone did not eliminate mating behavior; damage to both of these fiber systems was necessary to abolish copulation (Lehman, '82). Therefore, we hypothesized that chemosensory signals processed in $\mathrm{MeA}$ are relayed to $\mathrm{MeP}$, as well as to the bed nucleus of the stria terminalis, and that these areas, both of which have androgen-concentrating neurons and send axonal projections to the medial preoptic area (Maragos et al.,
Abbreviations

$\begin{array}{ll}\text { AAA } & \text { anterior amygdaloid area } \\ \text { ac } & \text { anterior commissure } \\ \text { AcbC } & \text { core of accumbens nucleus } \\ \text { AcbSh } & \text { shell of accumbens nucleus } \\ \text { ACo } & \text { anterior cortical nucleus } \\ \text { AD } & \text { anterodorsal nucleus of the thalamus } \\ \text { AH } & \text { anterior hypothalamus } \\ \text { AHA } & \text { amygdalohippocampal area } \\ \text { AL } & \text { anterolateral, bed nucleus of stria terminalis } \\ \text { alac } & \text { anterior limb of anterior commissure } \\ \text { AM } & \text { anteromedial, bed nucleus of stria terminalis } \\ \text { AOBgl } & \text { accessory olfactory bulb-glomerular layer } \\ \text { AOBgr } & \text { accessory olfactory bulb-granule cell layer } \\ \text { AOBm } & \text { accessory olfactory nulb-mitral cell layer } \\ \text { AONm } & \text { anterior olfactory nucleus, medial } \\ \text { AONv } & \text { anterior olfactory nucleus, ventral } \\ \text { Arc } & \text { arcuate nucleus of the hypothalamus } \\ \text { AV } & \text { anteroventral, bed nucleus of stria terminalis } \\ \text { BLa } & \text { basolateral amygdaloid nucleus, anterior } \\ \text { BLp } & \text { basolateral amygdaloid nucleus, posterior } \\ \text { BM } & \text { basomedial nucleus of the amygdala } \\ \text { BNSTal } & \text { bed nucleus stria terminalis, anterolateral } \\ \text { BNSTam } & \text { bed nucleus stria terminalis, anteromedial } \\ \text { BNSTav } & \text { bed nucleus stria terminalis, anteroventral } \\ \text { BNSTpi } & \text { posterointermedial bed nucleus stria terminalis } \\ \text { BNSTpl } & \text { posterolateral bed nucleus stria terminalis } \\ \text { BNSTpm } & \text { posteromedial bed nucleus stria terminalis } \\ \text { Ce } & \text { central amygdaloid nucleus } \\ \text { Cel } & \text { central amygdaloid nucleus, lateral } \\ \text { Cem } & \text { central amygdaloid nucleus, medial } \\ \text { CM } & \text { centromedial nucleus of the thalamus } \\ \text { CP } & \text { caudate-putamen } \\ \text { cp } & \text { cerebral peduncle } \\ \text { DM } & \text { dorsal medial hypothalamic nucleus } \\ \text { En } & \text { endopiriform nucleus } \\ \text { f } & \text { fornix } \\ \text { fr } & \text { fasiculus retroflexus } \\ \text { FS } & \text { fundus striati } \\ \text { GP } & \text { globus pallidus } \\ \text { HBl } & \text { lateral habenula } \\ \text { HDB } & \text { horizontal limb of the diagonal band of Broca } \\ \text { III } & \text { third ventricle } \\ \text { IM } & \text { intercalated mass cell group } \\ \text { LaTu } & \text { lateral tuberal nucleus } \\ \text { LH } & \text { lateral hypothalamus } \\ \text { lot } & \text { lateral olfactory tract } \\ \text { LPOA } & \text { lateral preoptic area } \\ & \\ & \end{array}$

\author{
dorsal lateral septum \\ intermediate lateral septum \\ ventral lateral septum \\ mediodorsal nucleus of the thalamus \\ medial nucleus of the amygdala, anterior \\ medial nucleus of the amygdala, anterodorsal \\ medial nucleus of the amygdala, anteroventral \\ medial nucleus of the amygdala, posterior \\ medial nucleus of the amygdala, posterodorsal \\ median preoptic nucleus \\ medial nucleus of the amygdala, posteroventral \\ medial preoptic nucleus \\ median preoptic nucleus, magnocellular \\ medial preoptic area \\ medial septum \\ mammillothalamic tract \\ nucleus of the accessory olfactory tract \\ nucleus of the lateral olfactory tract \\ optic chiasm \\ optic tract \\ olfactory tubercle \\ piriform cortex \\ posterointermedial, bed nucleus of stria terminalis \\ posterolateral, bed nucleus of stria terminalis \\ posterior limb of the anterior commissure \\ posterolateral cortical amygdaloid nucleus \\ postermedial, bed nucleus of stria terminalis \\ posteromedial cortical amygdaloid nucleus \\ dorsal premammillary nucleus of hypothalamus \\ ventral premammillary nucleus of hypothalamus \\ primary olfactory cortex \\ parataenial thalamic nucleus \\ paraventricular nucleus of the hypothalamus \\ paraventricular nucleus of the thalamus \\ nucleus reuniens of the thalamus \\ rhomboid nucleus of the thalamus \\ striatal cell bridges \\ suprachiasmatic nucleus \\ sublenticular substantia innominata \\ stria medullaris \\ supraoptic nucleus \\ stria terminalis \\ ventral amygdalofugal pathway \\ ventral limb of diagonal band of Broca \\ ventromedial hypothalamic nucleus \\ ventral pallidum
}


'89; Neal and Newman, '91a; Simerly and Swanson, '86), participate together in the normal regulation of behavior.

Although previous investigations have described the projections of Me (Krettek and Price, '78a,b; Kevetter and Winans, '81a), projections from the specific cytoarchitectonic subdivisions of $\mathrm{Me}$ have not been separately analyzed. Further, the relay of information from the chemosensoryrecipient $\mathrm{MeA}$ to the hormonally sensitive $\mathrm{MeP}$ would require specific projections that have not been reported within this nucleus. In the present investigation, the neuronal projections of MeA and $\mathrm{MeP}$ are separately identified using the anterograde neuronal tract tracer, Phaseolus vulgaris-leucoagglutinin (PHA-L).

\section{METHODS Surgery and perfusion}

Thirty-five adult male hamsters (2-3 months in age with body weights ranging between $110-120 \mathrm{~g}$ ) were obtained from Charles River (Wilmington, MA), housed in groups, and maintained on a 14 hour light: 10 hour dark illumination cycle with food and water ad libitum. The weight of the animal in these experiments was critical for obtaining accurate placement of injection sites by using predetermined stereotaxic coordinates. These animals were anesthetized with sodium pentobarbital ( $10 \mathrm{mg} / 100 \mathrm{~g}$ body weight), positioned in a stereotaxic apparatus with bregma and lambda in the same horizontal plane, and injected iontophoretically with $2.5 \%$ PHA-L (Vector Laboratories, Burlingame, CA) in $10 \mathrm{mM}$ sodium phosphate-buffered saline $(\mathrm{pH}=8)$ into Me. A vertical approach was used to reach this nucleus and was sufficiently lateral to avoid the exiting strial fibers caudally. Tracer was injected through a glass micropipette with internal diameter of 5-30 $\mu \mathrm{m}$ with $3-5$ $\mu \mathrm{A}$ of positive alternating current ( 7 seconds on/off) for 15 minutes. Stereotaxic coordinates for MeA injections were $0.5 \mathrm{~mm}$ rostral, $2.6 \mathrm{~mm}$ lateral, and $7.9 \mathrm{~mm}$ ventral to bregma. Those for $\mathrm{MeP}$ injections were: $0.5 \mathrm{~mm}$ caudal, 2.7 $\mathrm{mm}$ lateral, and $8.0 \mathrm{~mm}$ ventral to bregma.

After 10 days, animals were reanesthetized and transcardially perfused with $150 \mathrm{ml}$ of $0.9 \%$ sodium phosphatebuffered saline containing $0.1 \%$ sodium nitrite for vasodilation, followed by $250 \mathrm{ml}$ of $4 \%$ paraformaldehyde. Brains were removed and postfixed overnight at $4^{\circ} \mathrm{C}$ in $4 \%$ paraformaldehyde containing $20 \%$ sucrose for cryoprotection.

\section{Immunocytochemistry and analysis}

Coronal sections $(40 \mu \mathrm{m})$ were cut on a freezing microtome and collected in $0.02 \mathrm{M}$ potassium phosphate-buffered saline (KPBS) containing $0.01 \%$ sodium azide. Every fourth section was washed three times ( 5 minutes each) in KPBS containing $2 \%$ normal rabbit serum with $0.3 \%$ Triton- $\mathrm{X}$ and incubated in the primary antibody, goat anti-PHA-L (Vector Labs, Burlingame, CA), diluted to 1:1,000 in the same buffer for 48 hours at $4^{\circ} \mathrm{C}$. Sections were again washed and incubated with a secondary antibody, biotinylated rabbit anti-goat IgG (Vector Labs, Burlingame, CA) at 1:100 in the same buffer for 1 hour at room temperature. After subsequent washing in KPBS without normal rabbit serum and Triton-X, sections were incubated in the Elite Vectastain (Vector Labs, Burlingame, CA) avidin-biotin complex solution for 1 hour at room temperature. Sections were processed for 5-10 minutes in $0.0125 \%$ diaminobenzidine prepared in KPBS with $0.06 \%$ hydrogen peroxide. Nickel
TABLE 1. Comparison of Efferent Terminal Areas From Anterior and Posterior Parts of the Medical Amygdaloid-Nucleus

\begin{tabular}{|c|c|c|}
\hline & $\mathrm{MeA}$ & $\mathrm{MeP}$ \\
\hline \multicolumn{3}{|l|}{ Olfactory areas } \\
\hline accessory olfactory bulb-granule cell & + & - \\
\hline accessory olfactory bulb-mitral cell & + & - \\
\hline main olfactory bulb-granule cell & - & - \\
\hline main olfactory bulb-mitral cell & - & - \\
\hline anterior olfactory nucleus-dorsal & - & - \\
\hline anterior olfactory nucleus-medial & + & - \\
\hline anterior olfactory nucleus-ventral & + & - \\
\hline primary olfactory cortex & - & - \\
\hline dorsal transition area & - & - \\
\hline medial transition area & + & - \\
\hline ventral transition area & + & - \\
\hline endopiriform nucleus & + & - \\
\hline \multicolumn{3}{|l|}{ Thalamus } \\
\hline parataenial nucleus & + & - \\
\hline paraventricular nucleus & + & - \\
\hline mediodorsal nucleus & + & - \\
\hline lateral habenula & + & - \\
\hline nucleus reuniens & + & - \\
\hline \multicolumn{3}{|l|}{ Ventral forebrain } \\
\hline horizontal limb diagonal band & + & + \\
\hline vertical limb diagonal band & + & - \\
\hline nucleus accumbens-core & - & + \\
\hline nucleus accumbens-shell & + & - \\
\hline olfactory tubercle & + & - \\
\hline ventral pallidum & + & + \\
\hline sublenticular substantia innominata & + & - \\
\hline fundus striati & + & - \\
\hline \multicolumn{3}{|l|}{ Septum } \\
\hline lateral septum-dorsal & + & - \\
\hline lateral septum-intermediate & + & - \\
\hline lateral septum-ventral & + & + \\
\hline medial septum & + & - \\
\hline \multicolumn{3}{|l|}{ Bed nucleus of the stria terminalis } \\
\hline bed nucleus stria terminalis-anteromedial & + & + \\
\hline bed nucleus stria terminalis-anterolateral & - & - \\
\hline bed nucleus stria terminalis-anteroventral & + & + \\
\hline bed nucleus stria terminalis-posteromedial & - & + \\
\hline bed nucleus stria terminalis-posterointermediate & + & - \\
\hline \multicolumn{3}{|l|}{ Preoptic area and hypothalamus } \\
\hline medial preoptic nucleus & - & + \\
\hline medial preoptic area-medial & + & + \\
\hline medial preoptic area-lateral & + & - \\
\hline lateral preoptic area & + & - \\
\hline median preoptic area & + & + \\
\hline periventricular preoptic area & + & + \\
\hline lateral hypothalamus & + & - \\
\hline anterior hypothalamus & + & + \\
\hline periventricular nucleus & + & + \\
\hline paraventricular nucleus & + & + \\
\hline perifornical area & + & - \\
\hline ventromedial nucleus-core & + & - \\
\hline ventromedial nucleus-shell & - & + \\
\hline premammillary nucleus-ventral & + & + \\
\hline premammillary nucleus-dorsal & + & - \\
\hline lateral tuberal nucleus & + & - \\
\hline arcuate nucleus & + & + \\
\hline \multicolumn{3}{|l|}{ Amygdala } \\
\hline anterior medial nucleus & - & + \\
\hline posterior medial nucleus & + & - \\
\hline anterior amygdaloid area & + & + \\
\hline nucleus accessory olfactory tract & + & - \\
\hline nucleus lateral olfactory tract & + & - \\
\hline anterior cortical nucleus & + & + \\
\hline posterolateral cortical nucleus & + & - \\
\hline posteromedial cortical nucleus & + & + \\
\hline intra-amygdaloid bed nucleus stria terminalis & + & + \\
\hline intercalated mass & - & + \\
\hline central nucleus-medial & + & + \\
\hline basomedial nucleus & + & + \\
\hline amygdalohippocampal area & + & + \\
\hline basolateral posterior & + & - \\
\hline
\end{tabular}

chloride (final concentration $=\mathbf{0 . 0 1 5} \%$ ) was added to this solution to enhance the staining. The sections were subsequently rinsed in water, mounted out of KPBS, dehydrated, and coverslipped in Permount. All incubations and washes were carried out with gentle agitation. Adjacent sections were stained with cresyl-violet.

Sections were examined with bright and darkfield illumination on a Leitz Dialux microscope. Lectin-filled cells and 
MeA Injection Sites
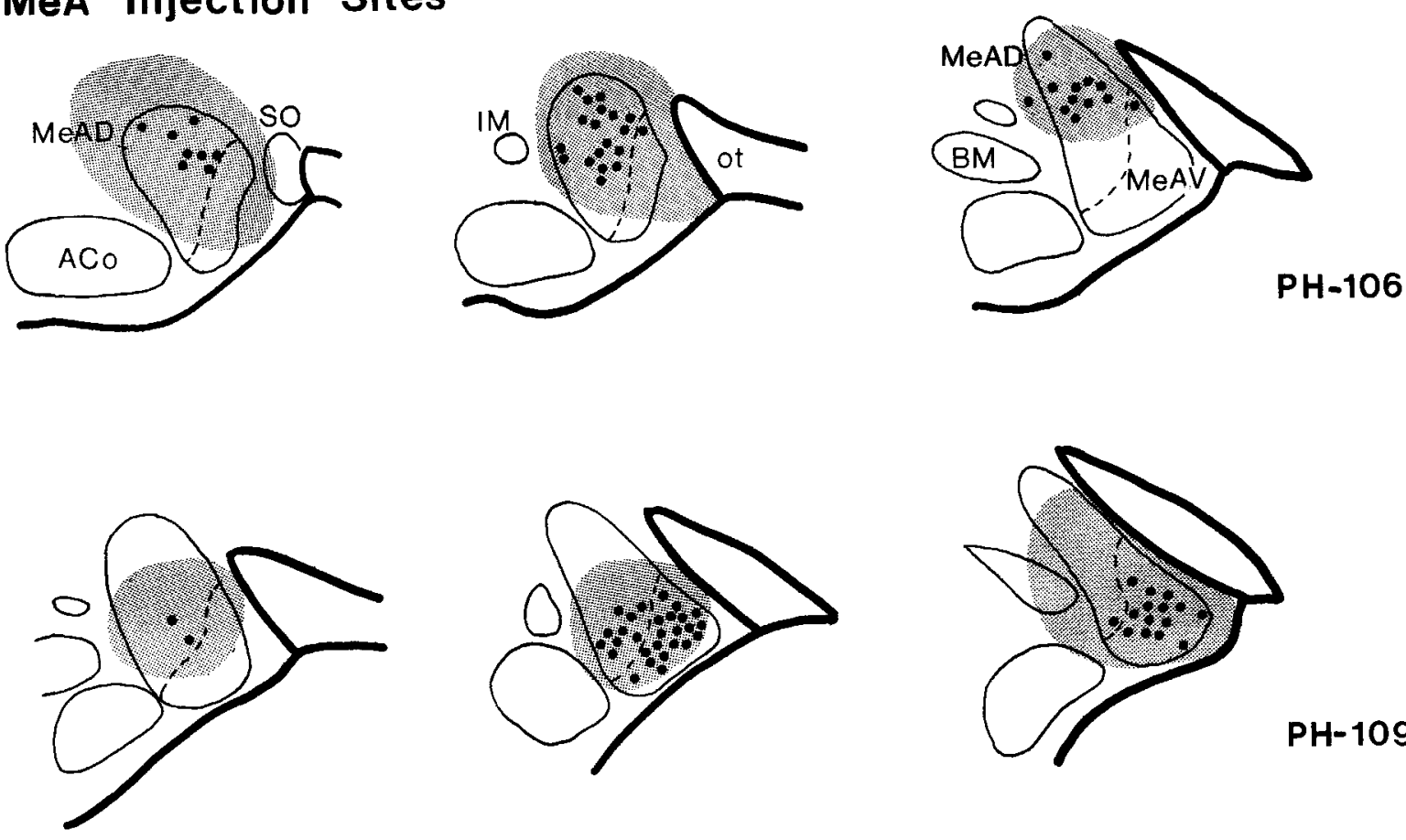

PH-109

\section{MeP Injection Sites}
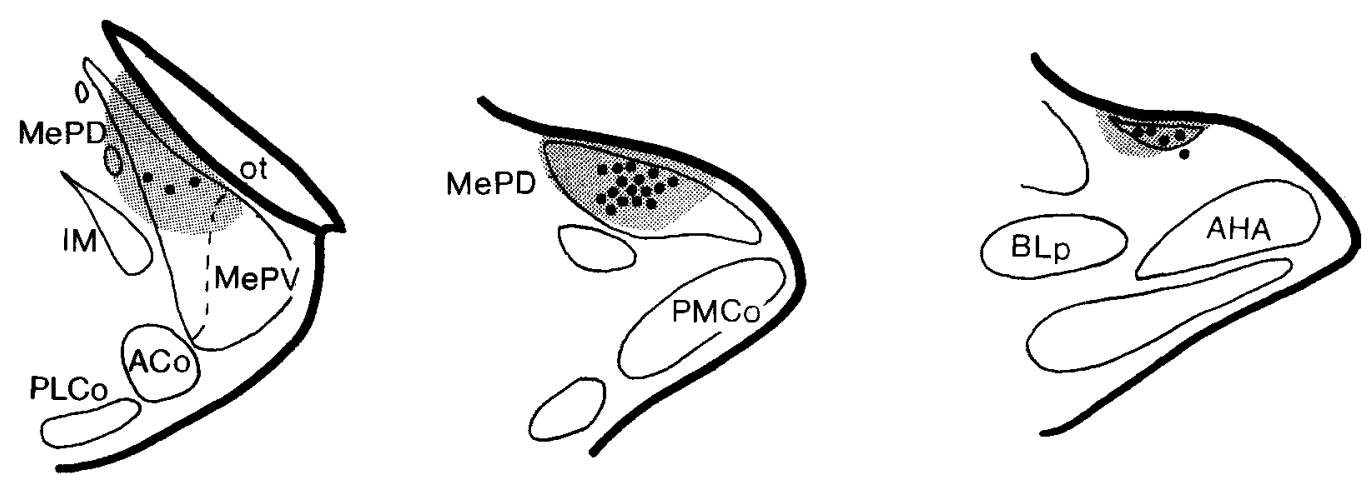

PH-68
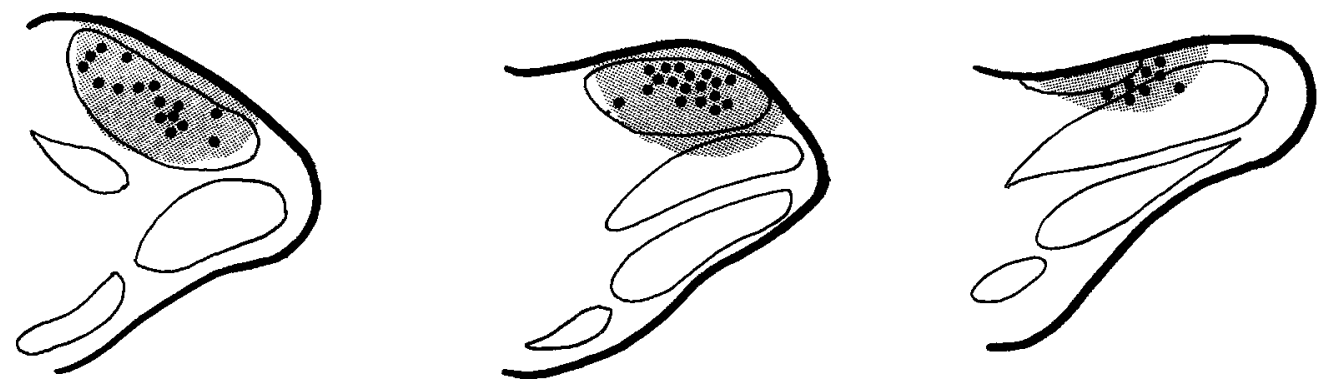

PH-59

Fig. 1. Schematic representation of the location of PHA-L-filled neurons (black dots) and the diffuse immunoreactivity of injection sites confined to MeA in experiments PH-106 and PH-109, and to MeP in experiments PH-68 and PH-59. Three rostral to caudal levels (left to right) are shown for each of the four brains. 

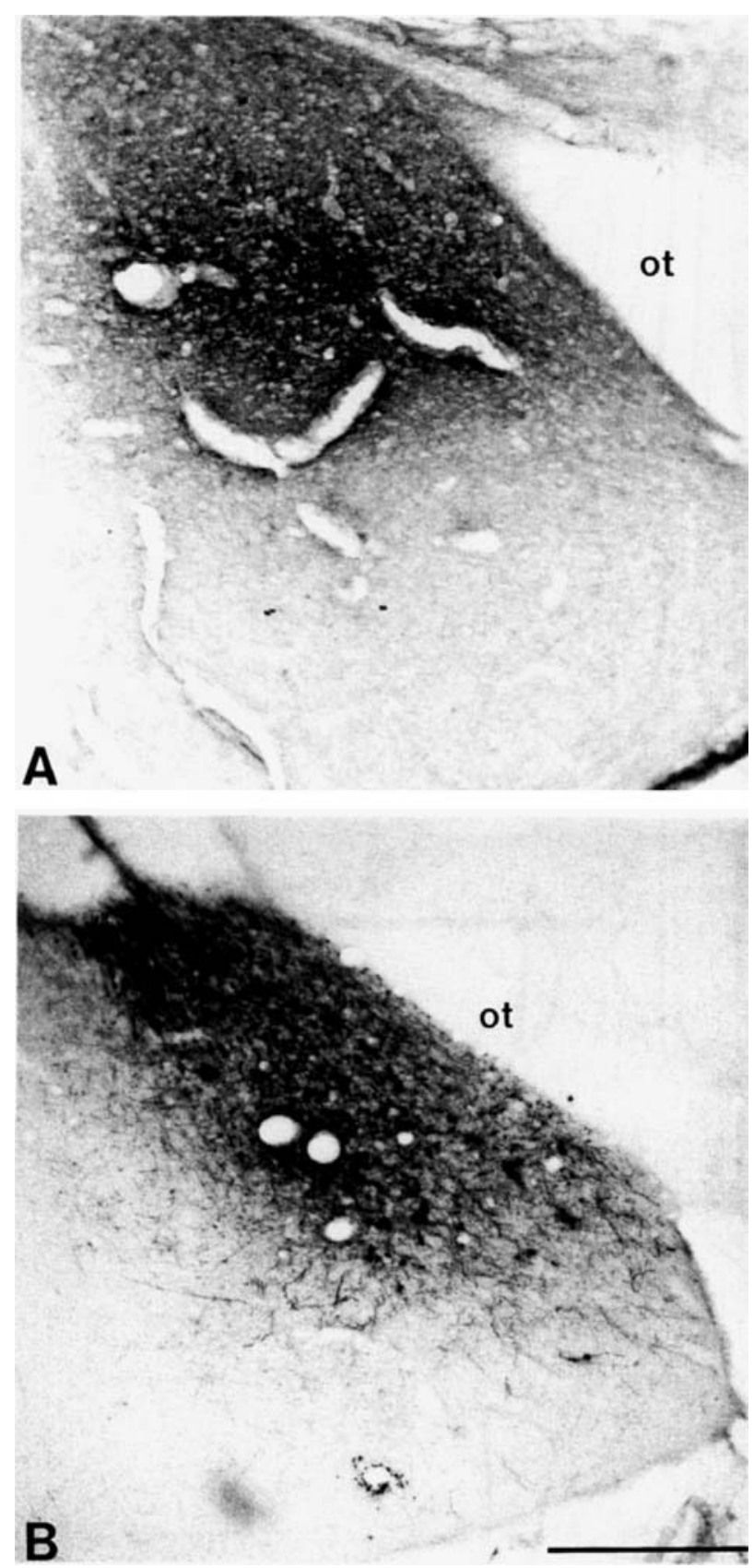

Fig. 2. Brightfield photomicrographs of coronal sections with PHA-L injection sites of MeA from PH-106 (A) and MeP from PH-59 (B). The injection site in MeA corresponds to the third schematic for PH-106 in Figure 1, whereas the injection site for $\mathrm{PH}-59$ corresponds to the first schematic in this same figure. Scale bar $=500 \mu \mathrm{m}$.

fibers with apparent terminals were plotted onto camera lucida tracings of adjacent Nissl-stained sections.

\section{RESULTS Injection sites}

Of the twenty-nine hamsters that had injection sites in $\mathrm{Me}$, four had injection sites confined to MeA and seven were in $\mathrm{MeP}$. The subdivisions of $\mathrm{Me}$ are similar to those in the

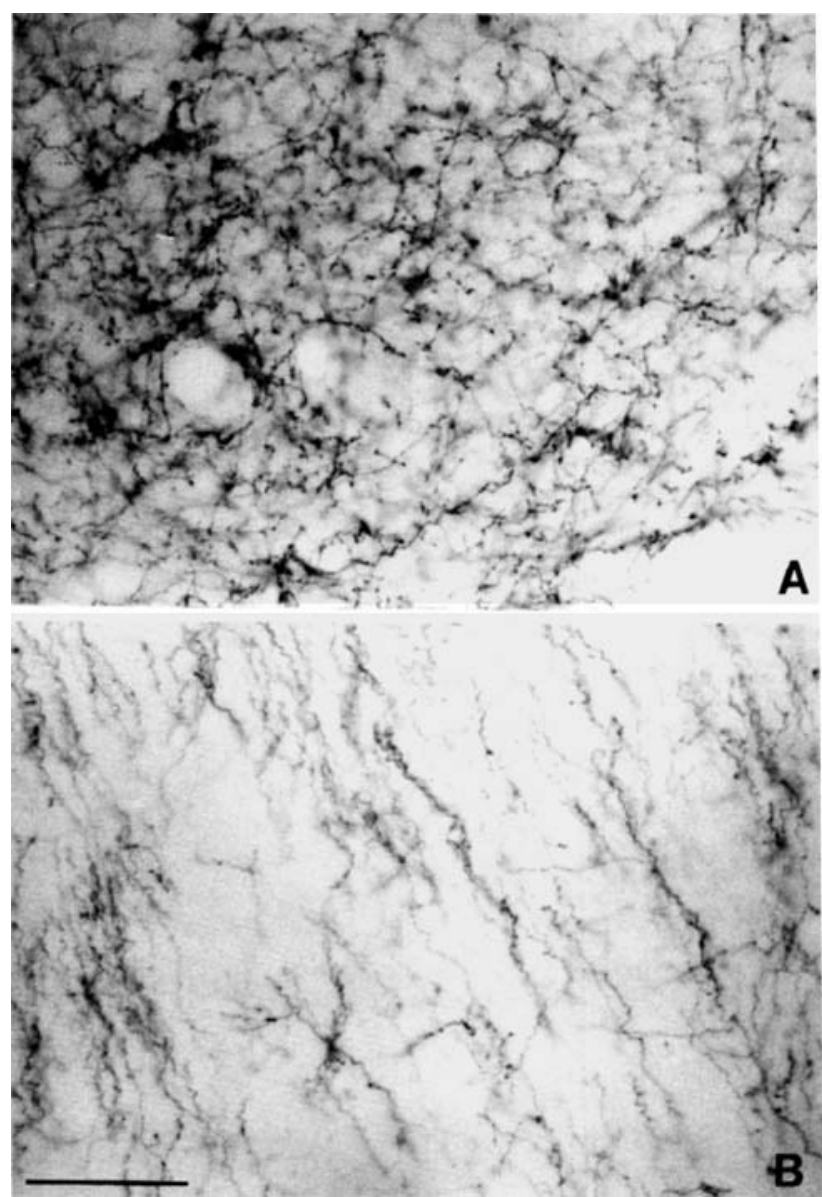

Fig. 3. High magnification brightfield photomicrographs of PHA-Llabeled fibers with varicosities and apparent terminals $(\mathbf{A})$ and fibers of passage (B). Scale bar $=50 \mu \mathrm{m}$.

rat (Paxinos, '85) and correspond to those previously described for the hamster (Gomez and Newman, '91a). Examples of these specific injection sites are shown in Figure 1. Seven additional animals had injections which included and surrounded MeA rostrally and dorsally but did not include MeP. These animals were used as controls to compare the projections with those of animals with confined MeA injection sites. Four animals had injections in MeP plus amygdalohippocampal area and/or posteromedial cortical nucleus, and these were used for comparison and to confirm the projections of MeP. Finally, seven animals had PHA-L deposited in both $\mathrm{MeA}$ and $\mathrm{MeP}$. The injection sites ranged between $200-1,000 \mu \mathrm{m}$ in diameter. They included densely labeled neurons in the center of the injection site and diffuse staining in the surrounding neuropil (Fig. 2). Labeled axonal fibers emerging from the cells were often observed.

\section{Axonal projections}

Efferents of Me followed either one of the two major pathways, the ventral amygdalofugal pathway, rostrally, or the stria terminalis, caudally. Neither one of these pathways contained projections from MeA or MeP exclusively. Although some labeled fibers were observed on the contralateral side of the injection site, the labeled fibers were 


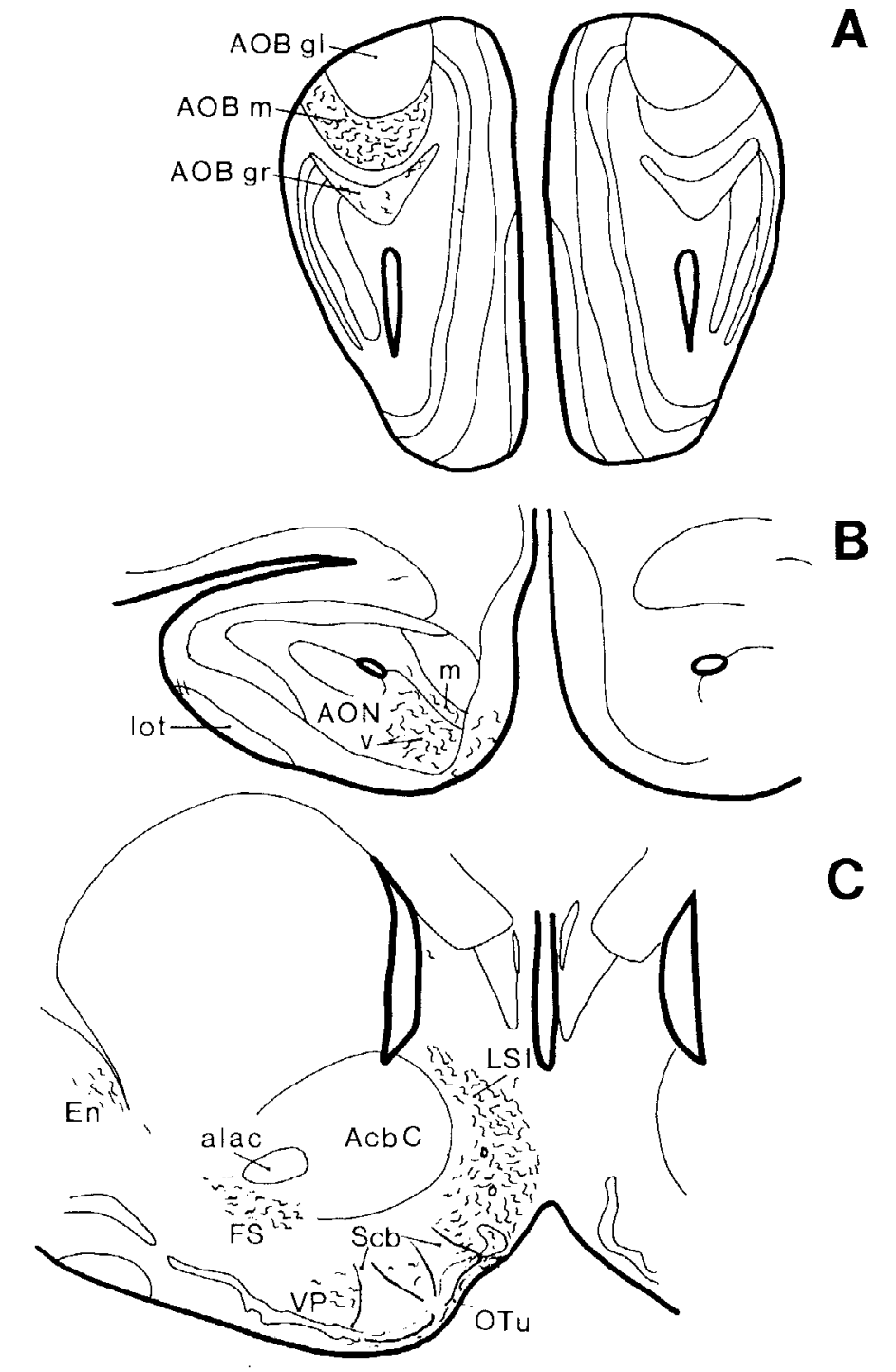

A

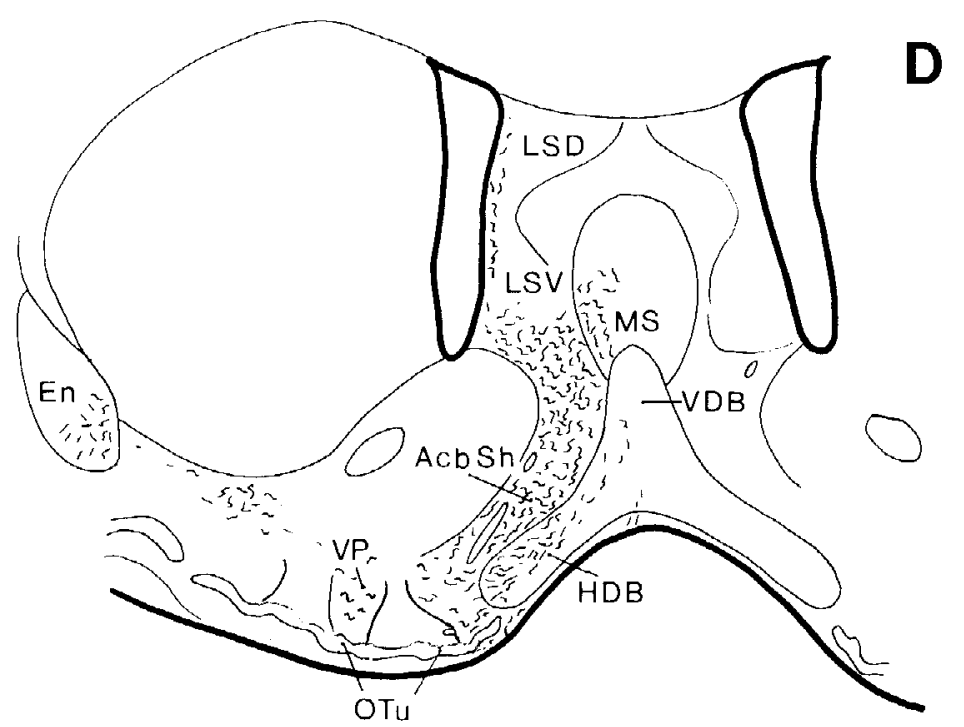

Fig. 4. Schematic drawings (A-M) of the distribution of fibers throughout the forebrain after injections of PHA-L confined to MeA inPH-106. Short curved lines represent terminal fields whereas straight lines represent axons of passage. 


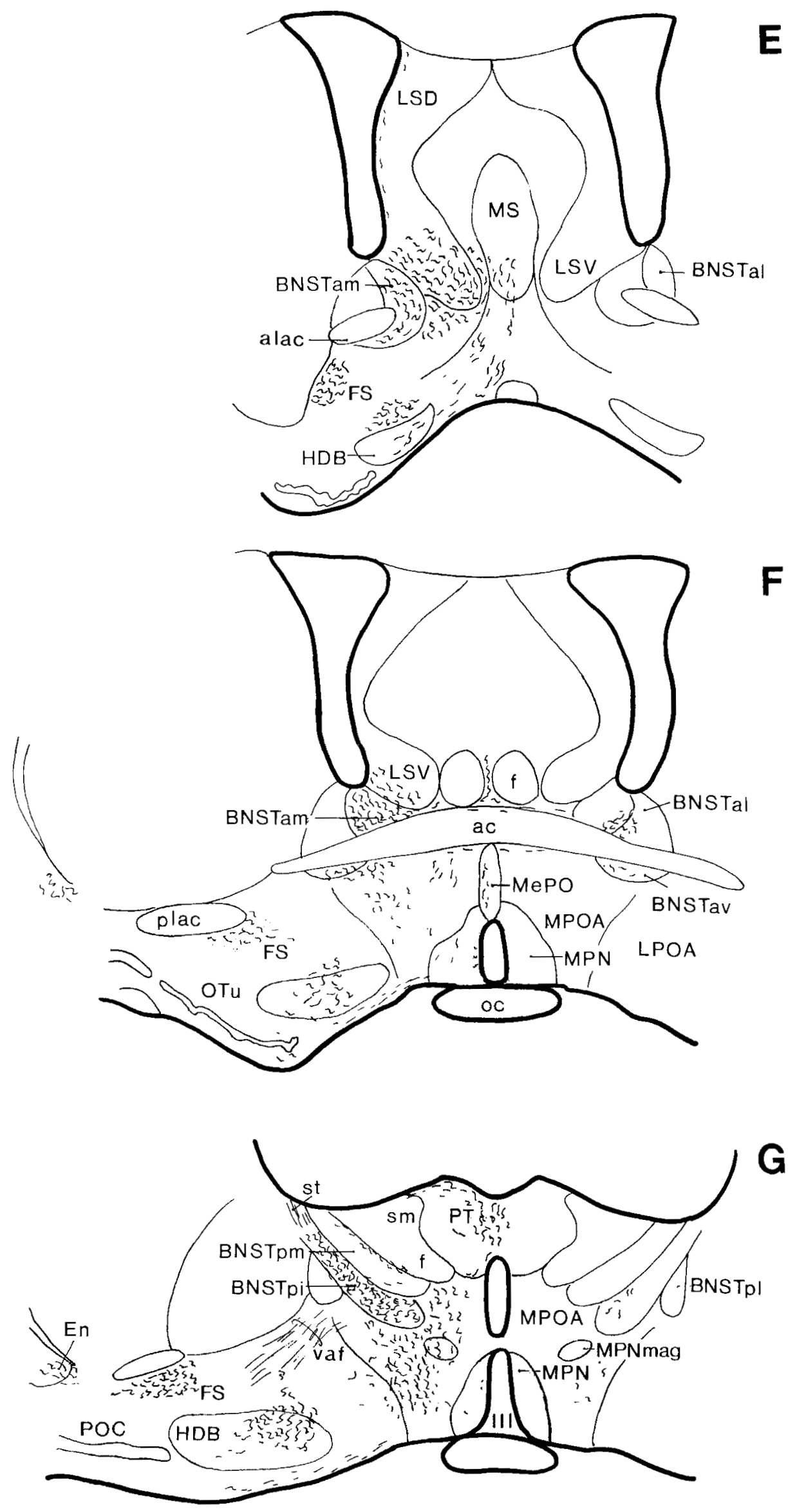

Fig. 4 continued 

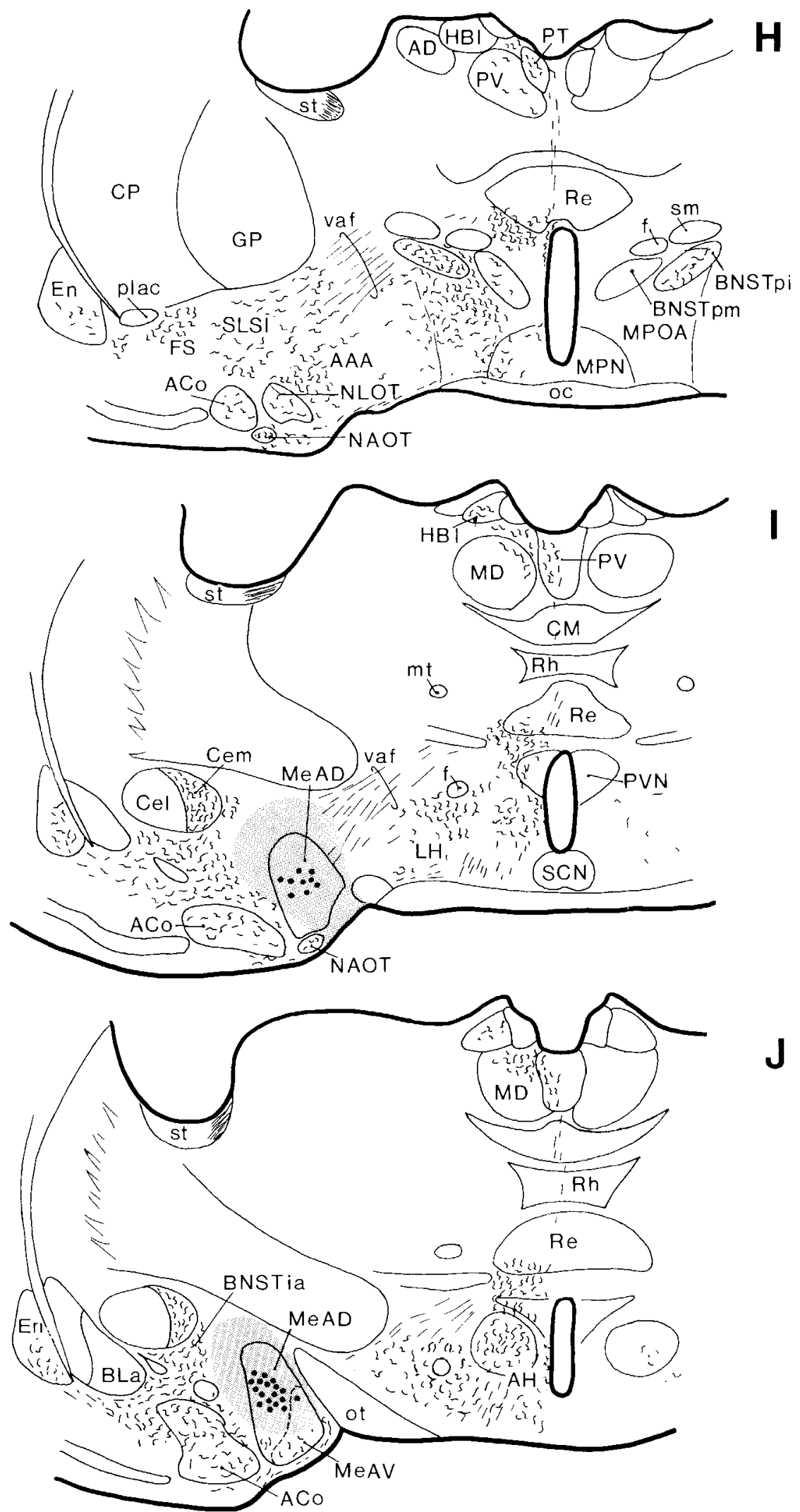

Figure 4 continued 


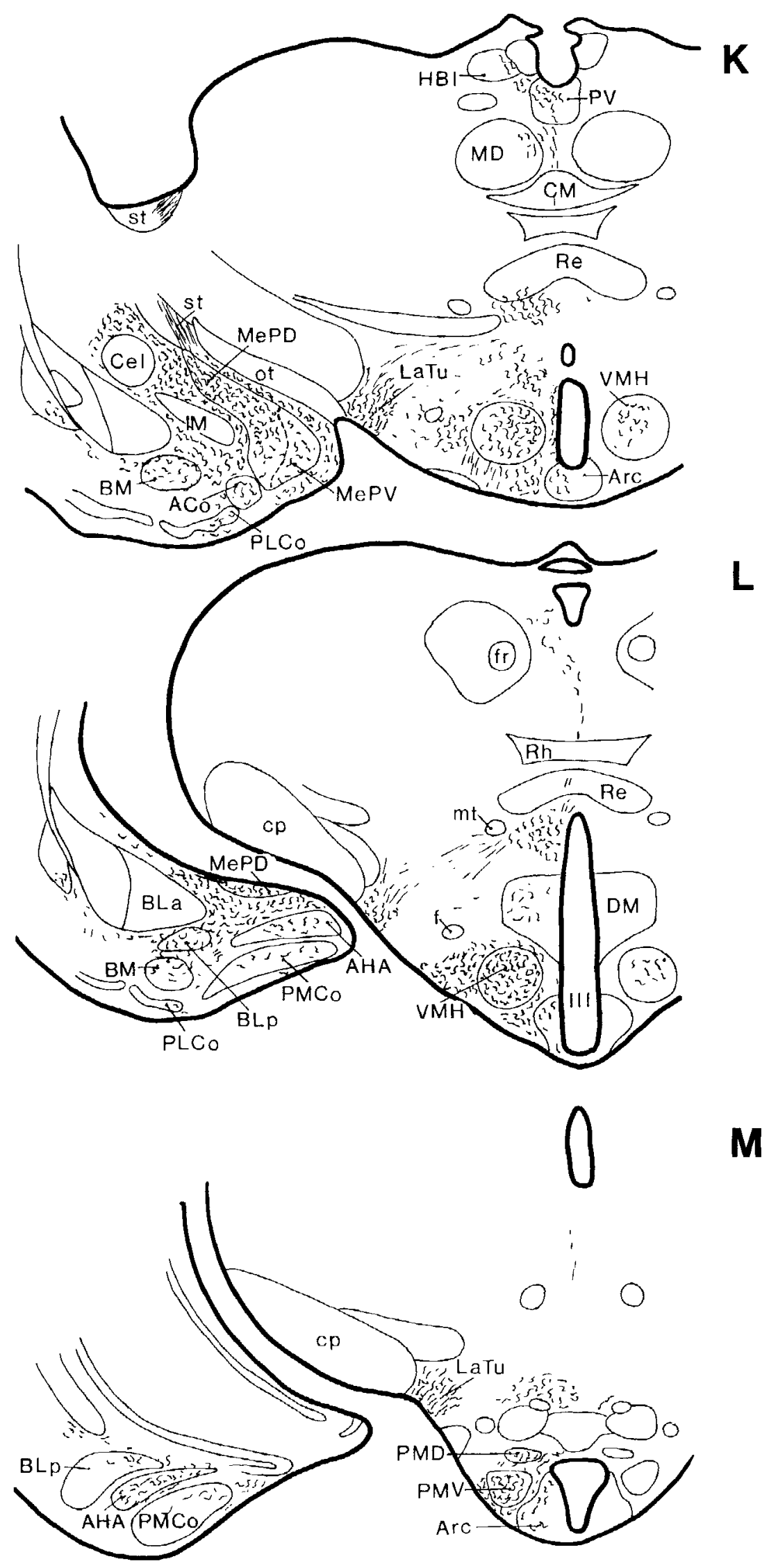

Fig. 4 continued 
predominantly ipsilateral. Cells from both subregions of $\mathrm{Me}$ projected to the same general territories previously identified in the hamster (Kevetter and Winans, '81a; Maragos et al., '89); however the present study revealed that $\mathrm{MeA}$ and $\mathrm{MeP}$ had specific terminal areas within these territories. In addition, cells in MeA had projections not previously reported in the hamster. Target areas were identified by the presence of varicosities along the axons and axonal branches bearing apparent terminal boutons (Fig. 3A). The density of fibers in a given target area varied and was not always related to the size of the injection site. Fibers that coursed in parallel, with little or no branching and few varicosities or terminal boutons were generally regarded as "fibers of passage" (Fig. 3B). Table 1 summarizes the results of this study. The following sections describe, in detail, the projections of the anterior and the posterior parts of the medial amygdaloid nucleus. Also included are descriptions of the cytoarchitecture of several nuclei that receive terminals from $\mathrm{MeA}$ and $\mathrm{MeP}$ to enable comparison with the corresponding regions in the rat.

Anterior medial amygdaloid nucleus projections. The distribution of labeled fibers and terminals was assessed in animals that had injection sites confined to MeA (Fig. 1) and was compared to those with injection sites centered in $\mathrm{MeA}$ but that also included a few labeled neurons in adjacent areas. These latter injection sites are not shown. They included small numbers of neurons in either the anterior amygdaloid area, sublenticular substantia innominata, or the nucleus of the accessory olfactory tract. The target areas identified for MeA were common to all the brains with PHA-L deposited in this region.

The distribution of labeled fibers from animal PH-106 is shown in Figure 4. The most rostral projections of these neurons were within the mitral cell layer of the accessory olfactory bulbs where many fibers and terminals were observed (Fig. 4A). These projections were primarily ipsilateral. Sparse fibers with varicosities were also found within the granule cell layer of the accessory olfactory bulb. These fibers reach their target areas via the lateral olfactory tract. Fibers were also seen in the medial and ventral parts of the anterior olfactory nucleus (Fig. 4B).

$\mathrm{MeA}$ axons project to a dense terminal field in the rostralmost extent of the intermediate part of the lateral septum, dorsomedial to the rostral nucleus accumbens, as well as to the medial part of the shell of nucleus accumbens (Fig. 4C,D). Occasional fibers were found within the lateral part of the shell of nucleus accumbens (Fig. 4D) and, at this same level, in the medial part of the olfactory tubercle although many fibers in the superficial layer of the tubercle appeared to be fibers of passage that were travelling rostrally. Fibers were also located in the deep layers of the olfactory tubercle. A separate group of fibers located laterally were identified as belonging to the fundus striati (Fig. $5 \mathrm{~B}$ ). These ventrostriatal inputs extended throughout its rostral to caudal extent (Fig. 4C-H). Fibers were sparsely distributed within the ventral pallidum between the striatal cell bridges (Figs. 4C-E, 5A). In addition fibers were observed deep to the primary olfactory cortex within the endopiriform nucleus throughout its rostral to caudal extent (Fig. 4C-M); however, few varicosities were found on these fibers.

Within the diagonal band, some labeled fibers were found in the vertical limb and a greater number in the horizontal limb (Fig. 4D-G). Both fibers of passage and those with many boutons were noted, with the latter concentrated outside the nuclear area, along the ventromedial surface of the brain. Continuous with the vertical limb of the diagonal
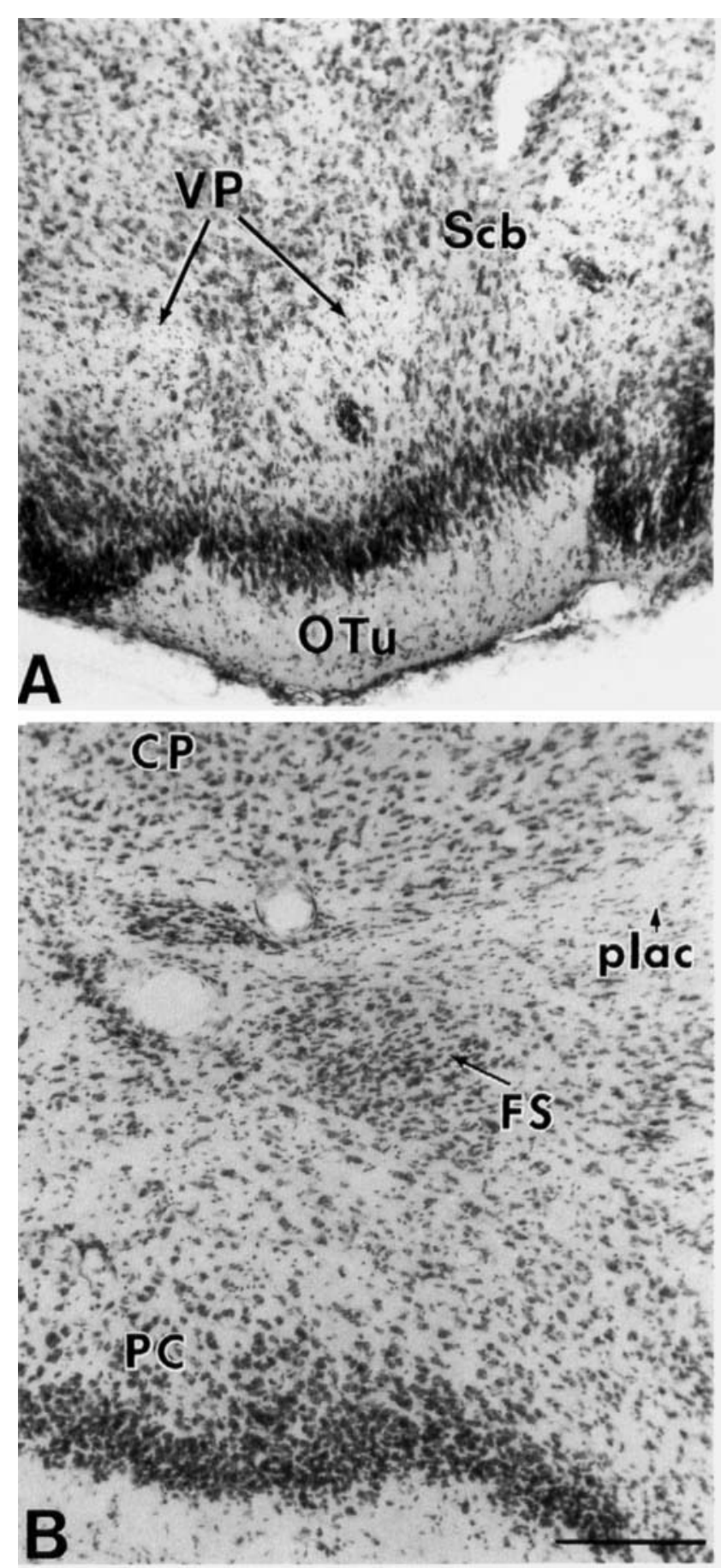

Fig. 5. Photomicrographs of Nissl-stained sections at the level of the ventral pallidum and intervening striatal cell bridges $(A)$ and the fundus striati $(\mathbf{B})$. Scale bar $=200 \mu \mathrm{m}$.

band dorsally, occasional fibers and terminals were found in the medial septum. Fibers and terminals were also found in the ventral, intermediate, and, less extensively, in the dorsal parts of the lateral septum.

The anterior part of the bed nucleus of the stria terminalis, rostral to and at the level of the body of the anterior commissure, was a target for MeA terminals. Within this region, MeA fibers and terminals were distributed medially to the anteromedial region (Figs. $4 \mathrm{~F}, 6 \mathrm{~A}$ ), which lies dorsal 


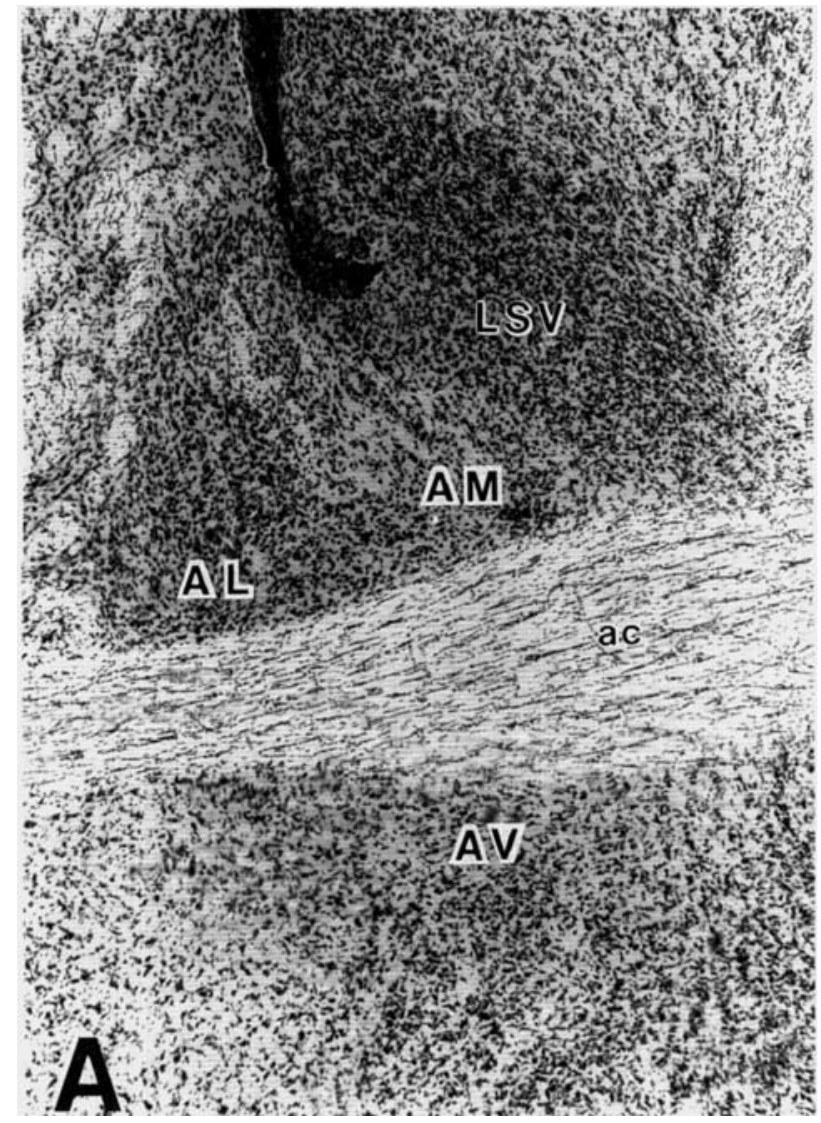

to, and extends rostral to the anterior commissure. MeA fibers also terminated below the body of the anterior commissure, in the medial part of the anteroventral region. They did not terminate in any part of the lateral region of the anterior bed nucleus.

In Nissl-stained material, the anteromedial region is characterized by small to medium-sized cells that are moderately sparse in packing density compared to the adjacent anterolateral region of the bed nucleus and the more medially situated ventrolateral septum (Fig. 6A). This anteromedial subdivision corresponds to the anteromedial region of the bed nucleus in the rat described by Moga et al. ('89). The anteroventral region of the bed nucleus is heterogenous in cell types, cell packing density, and cell orientation as observed in Nissl-stained sections. This subcommissural region consists of several subnuclei. The medial part of this anteroventral region appears to be most similar in connections to the anteromedial region above the commissure and may actually be a ventral extension of this anteromedial part of the bed nucleus. This subnucleus corresponds to the ventromedial part of the medial bed nucleus described by Moga et al. ('89).

Labeled fibers within the stria terminalis extending into the bed nucleus suggested that MeA efferents reach the anteromedial and the medial part of the anteroventral area via this fiber bundle. A small number of fibers crossed at the caudal border of the body of the anterior commissure to terminate in the contralateral bed nucleus (Fig. 7), a finding that confirms previous studies in the rat and hamster (Heimer and Nauta, '69; De Olmos, '72; Kevetter and Winans, '81a).

A surprising finding was the paucity of terminal fields within the medial division of the posteromedial bed nucleus, immediately adjacent to the stria medullaris and
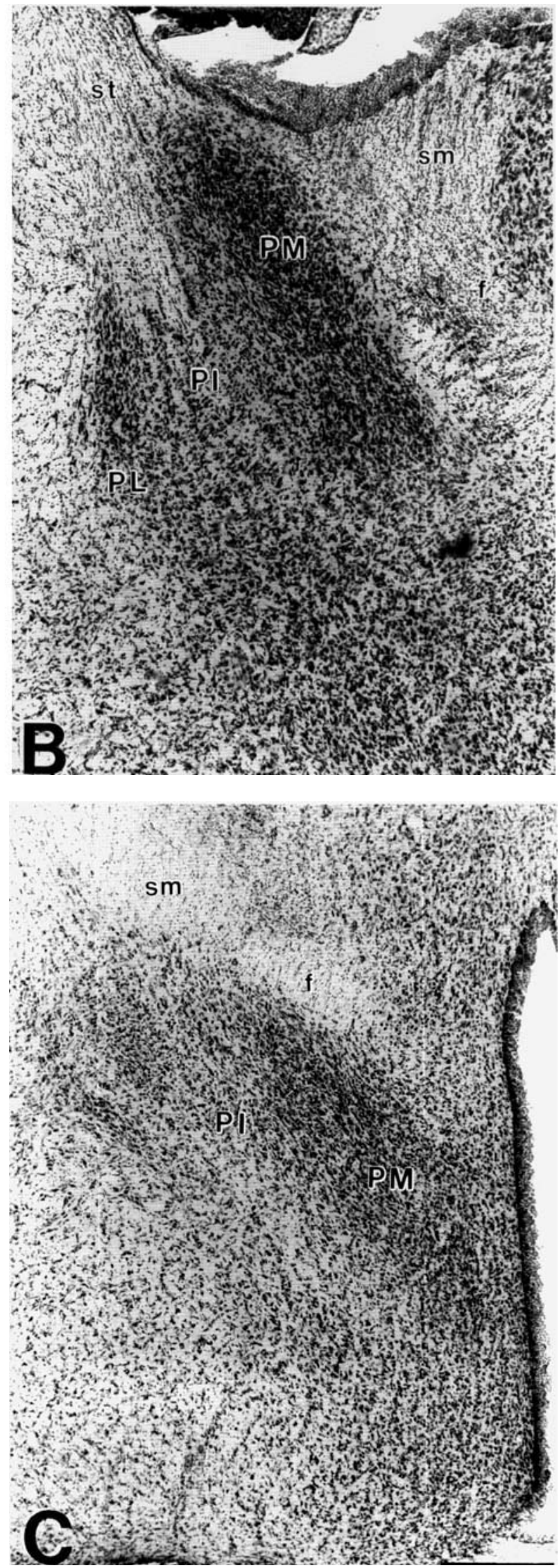

Fig. 6. The subdivisions of the bed nucleus of the stria terminalis are shown in these photomicrographs of Nissl-stained sections at three different rostral to caudal levels $(\mathbf{A}-\mathbf{C})$. Scale bar $=350 \mu \mathrm{m}$. 
fornix (Fig. 4G). Fibers appeared to surround this nucleus. In contrast, at this rostro-caudal level the intermediate portion of the posterior bed nucleus of the stria terminalis received a substantial input from $\mathrm{MeA}$ (Fig. 8). This region of the bed nucleus of the stria terminalis (Fig. 6B) corresponds cytoarchitecturally to the descriptions of the posterointermediate part of the medial division of the bed nucleus by Moga et al., (' 89 ), to the transverse and interfascicular nuclei of $\mathrm{Ju}$ and Swanson, ('89), and to the lateral cell column of the posteromedial division plus the posterior part of the intermediate division of this nucleus of De Olmos et al., ('85) in the rat. In earlier studies of the hamster, this area has been designated as the lateral bed nucleus of the stria terminalis (Lehman and Winans, ' 83 ; Powers et al., '87; Maragos et al., '89).

This pattern of fiber labeling in the posterointermediate division also extended caudally into the preoptic bed nucleus (Fig. $4 \mathrm{H}$ ), whereas the posteromedial division of the preoptic bed nucleus of the stria terminalis was free of fiber labeling after injections into MeA. Neither Moga et al. ('89) nor Ju and Swanson ('89) describe cytoarchitecturally an equivalent region in the rat. De Olmos et al. ('85), however, discuss a medial and an intermediate extension of the posterior division into the preoptic bed nucleus in the rat, which appears to be similar to that observed in the hamster (Fig. 6C). As in the rostral part of the bed nucleus, a few fibers and terminals were present in the corresponding areas contralaterally.

The distribution of labeled fibers in the preoptic region was similar to that observed in the bed nucleus of the stria terminalis in that from the mid-rostral to the caudal extent of the medial preoptic area, a greater concentration of fibers and terminals were present in the lateral than in the medial part of the medial preoptic area, and this fiber system extended into the lateral preoptic area proper (Figs. $4 \mathrm{G}, 4 \mathrm{H}$, 9). In contrast to this predominantly lateral distribution, within the rostral preoptic region, ventral to the body of the

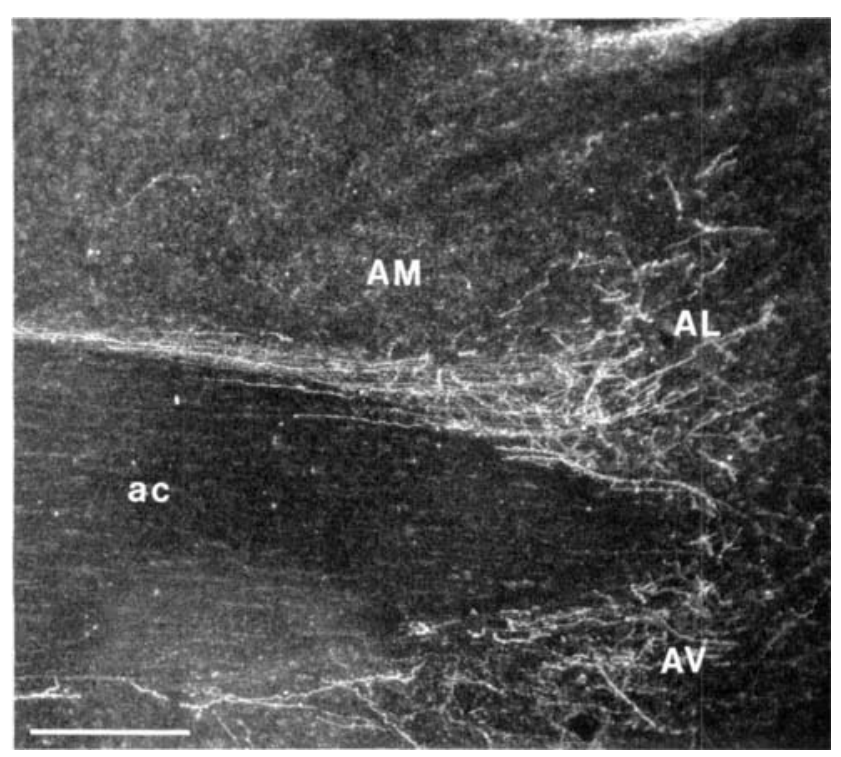

Fig. 7. Darkfield photomicrograph of PHA-L fibers in the contralateral bed nucleus of the stria terminalis, at the level of the body of the anterior commissure. The fibers appear to reach this area by crossing dorsal and ventral to the body of the anterior commissure. Beginning at this level and extending posteriorly, more fibers are found in the lateral part of the bed nucleus bilaterally. Scale bar $=200 \mu \mathrm{m}$. anterior commissure, the median and periventricular preoptic nuclei received $\mathrm{MeA}$ afferents and the lateral zone of the medial preoptic area received sparse fibers at this level. Along the ventromedial surface of the brain, numerous fibers, travelling rostrally and parallel to the pial surface, appeared to be projecting towards the midline. After $\mathrm{MeA}$ injections, the ventral amygdalofugal pathway and the stria terminalis were both distinctly labeled and both appeared to contribute some fibers that terminated in the bed nucleus and the preoptic area caudal to the anterior commissure, and others that continued through the preoptic region to reach caudal targets in the hypothalamus.

Throughout the medial and lateral hypothalamus, many fibers and terminals were present (Fig. 4I-M). The core of the ventromedial nucleus of the hypothalamus, which consists of several subnuclei, received substantial input from MeA (Fig. 10A). Surrounding this core, the cell sparse shell of the ventromedial nucleus contained fibers of passage as well as a few terminals. In addition, the ventral premammillary and the lateral tuberal nuclei of the hypothalamus also contained the heavy labelling of terminal fields (Fig. 4K-M). Additional targets of MeA included the paraventricular, periventricular, arcuate, dorsal premammillary, and perifornical nuclei of the hypothalamus.

Within the thalamus, midline nuclei were recipients of MeA efferents (Fig. 4G-K). These included parataenial, paraventricular, reuniens, and an unidentified thalamic region ventral to nucleus reuniens. The mediodorsal nucleus and lateral habenula also received MeA input. In the centromedial and rhomboid nuclei vertically coursing fibers from the amygdala were primarily fibers of passage. Fibers reached all of these thalamic targets either by exiting the stria terminalis to enter the stria medullaris or by ascending from the caudally coursing fiber bundle within the medial hypothalamus. This fiber pathway within the medial hypothalamus has been described as part of the ventral amygdalofugal system (De Olmos, '72; Price et al., '87).

In addition to the rostral telencephalic and diencephalic targets described above, several nuclei within the amygdaloid complex were consistently labeled (Fig. 4G-L) after PHA-L injection in MeA. Rostrally, both the ipsilateral nuclei of the accessory olfactory tract and lateral olfactory tract had labeled fibers within their cell and molecular layers (Fig. 4H,I). Sparse fibers were distributed within the sublenticular substantia innominata and the anterior amygdaloid area (Fig. 4H). Fiber labeling within the amygdala was found in the intra-amygdaloid portion of the bed nucleus of the stria terminalis, and in olfactory areas including the molecular and cell layers of the anterior cortical nucleus and sparse fibers in the posterolateral cortical nucleus. Fibers also were found in the posteromedial cortical nucleus and among the cells of the amygdalohippocampal area (Fig. 4L-M).

Finally, MeP received heavy fiber labeling from $\mathrm{MeA}$ (Figs. 4K-L, 11) and although many terminals were noted in the medial molecular layer of $\mathrm{MePD}$, some of these fibers were coursing through to enter the stria terminalis. Thus, MeA appears to provide substantial input to other vomero-

Fig. 8. Low- and high-powered brightfield photomicrographs of PHA-L-labeled fibers in the intermediate subregions of the posterior bed nucleus of the stria terminalis $(\mathrm{PI})$ after injections in MeA of animal PH-54 (A,B) and in the posteromedial part of the bed nucleus (PM) after injections in MeP of animal PH-59 (C,D). * indicates corresponding areas in figures $A-D$. Scale bar $(A, C)=300 \mu \mathrm{m},(B, D)=100 \mu \mathrm{m}$. 

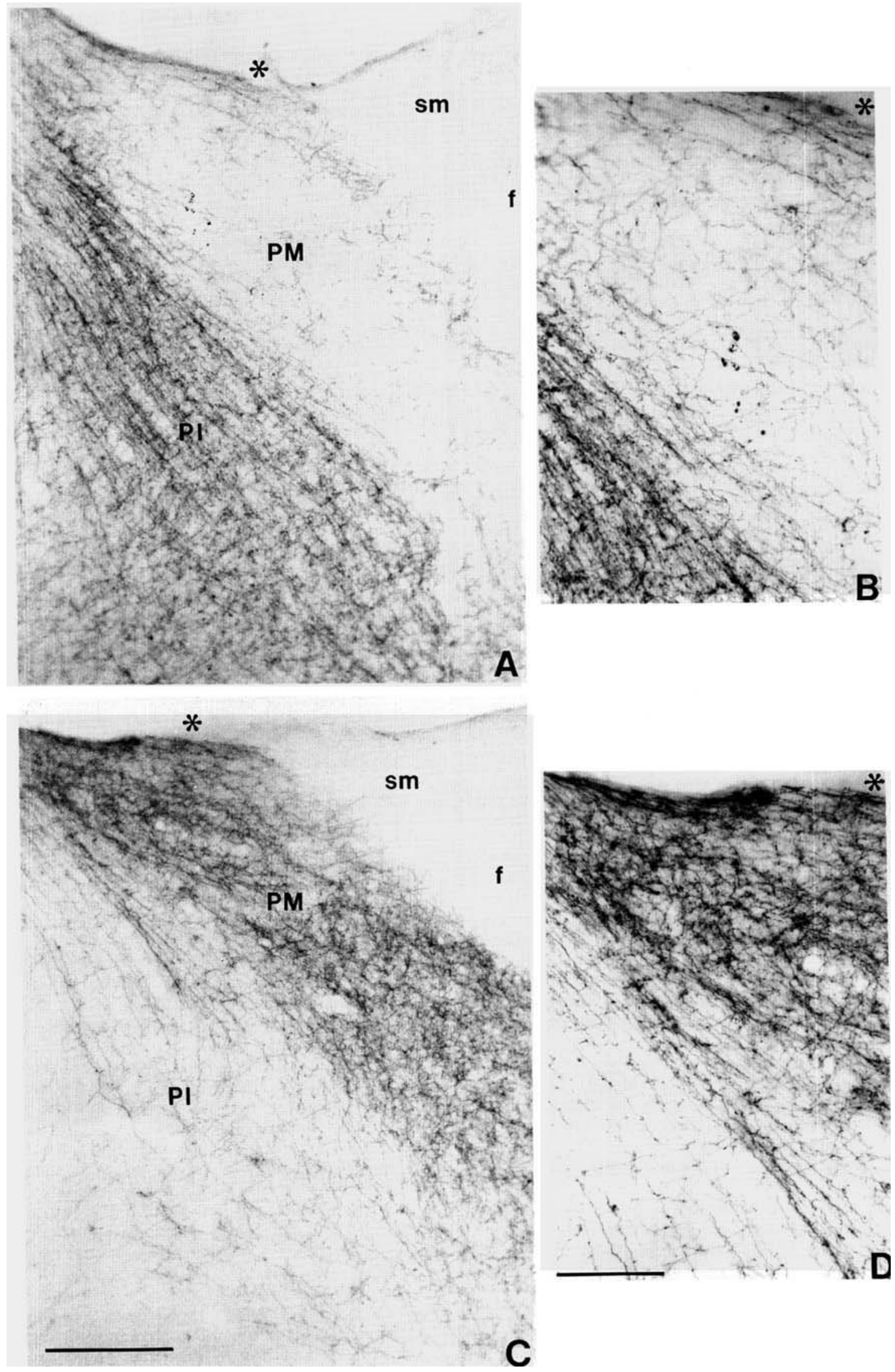


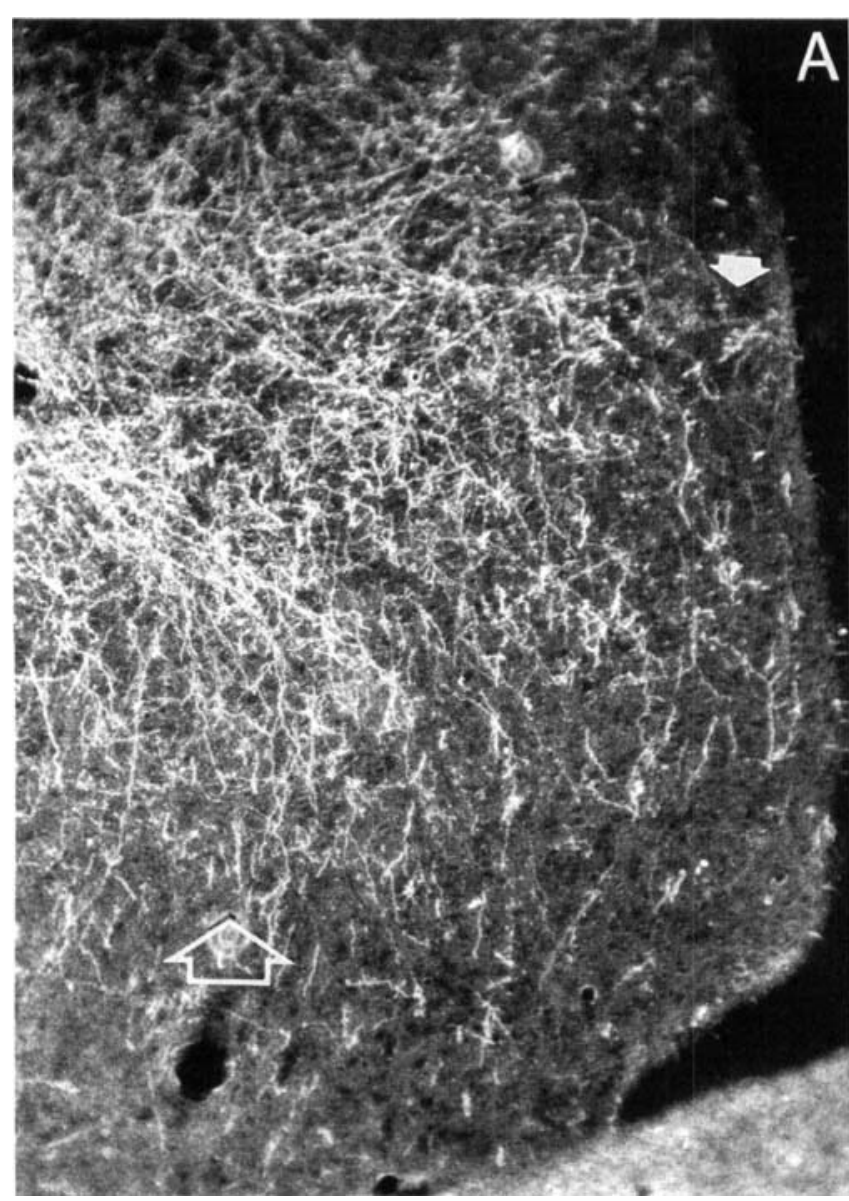

Fig. 9. Darkfield photomicrographs of the fiber distribution within the medial preoptic area. Fibers were concentrated within the lateral part of the medial preoptic area after injections in MeA (A; PH-106), whereas fibers were concentrated within the medial preoptic nucleus

nasal system targets within the amygdala via its input to $\mathrm{MeP}$ and the posteromedial cortical nucleus. Contralateral projections were sparse within dorsal MeA and intraamygdaloid bed nucleus of the stria terminalis. Lastly, moderate fiber labeling was observed in the basomedial nucleus and few terminals were found in the posterior part of the basolateral nucleus (Fig. 4M).

In experiment $\mathrm{PH}-109$, the injection site was primarily confined to the ventral part of MeA (MeAV). The labeling pattern was similar to $\mathrm{PH}-106$ with the absence of fiber labeling in the thalamus, anterior olfactory nucleus, ventral diagonal band, and ventral pallidum.

Posterior medial amygdaloid nucleus projections. The projections of MeP from animal PH-59 are presented on Figure 12A $-\mathrm{J}$. The projections in this animal were representative of the seven animals that had labeled cells confined to $\mathrm{MeP}$ (Fig. 1), even though, in the caudalmost extent of this injection site, a few labeled neurons were identified in the amygdalohippocampal area. Rostrally, fibers were observed in the caudomedial aspect of nucleus accumbens, medial to the anterior limb of the anterior commissure, although these fibers may be associated with the rostralmost extent of the bed nucleus of the stria terminalis. A few fibers were observed in the ventral aspect of the lateral septum. The

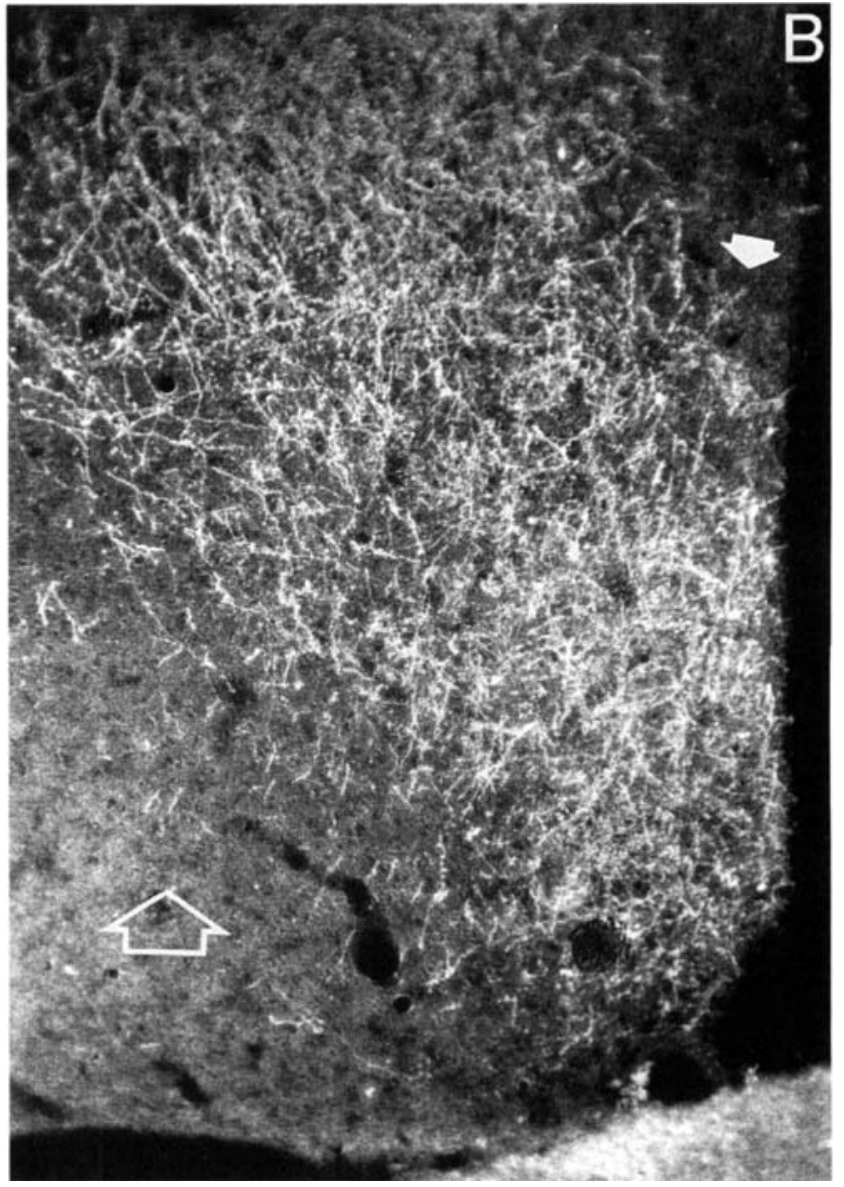

medially after injections in $\mathrm{MeP}$ (B; PH-59). A comparison of these differences within the medial and lateral parts of the medial preoptic area is shown with filled and open arrows respectively. Scale bar $=500$ $\mu \mathrm{m}$.

horizontal limb of the diagonal band was also a target of MeP neurons (Fig. 12A).

Fibers with terminal boutons were found throughout the anteromedial bed nucleus of the stria terminalis beginning rostral to the anterior commissure as shown in Figure 12A. Unbranched fibers without boutons were also found arching over the medial aspect of the anterior limb of the anterior commissure through to the medial bed nucleus of the stria terminalis. Many of these were presumably strial fibers also travelling to more caudal targets. At the level of the anterior commissure, abundant terminalis were observed in the anteromedial bed nucleus of the stria terminalis, immediately ventral to the lateral ventricle, and a moderate number were also found in the medial part of the anteroventral bed nucleus, ventral to the anterior commissure (Figs. 12B, 6A). Occasional fibers and terminals were observed in the contralateral anteromedial bed nucleus of the stria terminalis at this rostro-caudal level. Fibers reached these contralateral targets by coursing through the stria terminalis and then either along the dorsal or ventral border of the body of the anterior commissure.

The heaviest plexus of branched axons and terminal boutons of all the MeP targets was found in the medial part of the posteromedial bed nucleus of the stria terminalis 

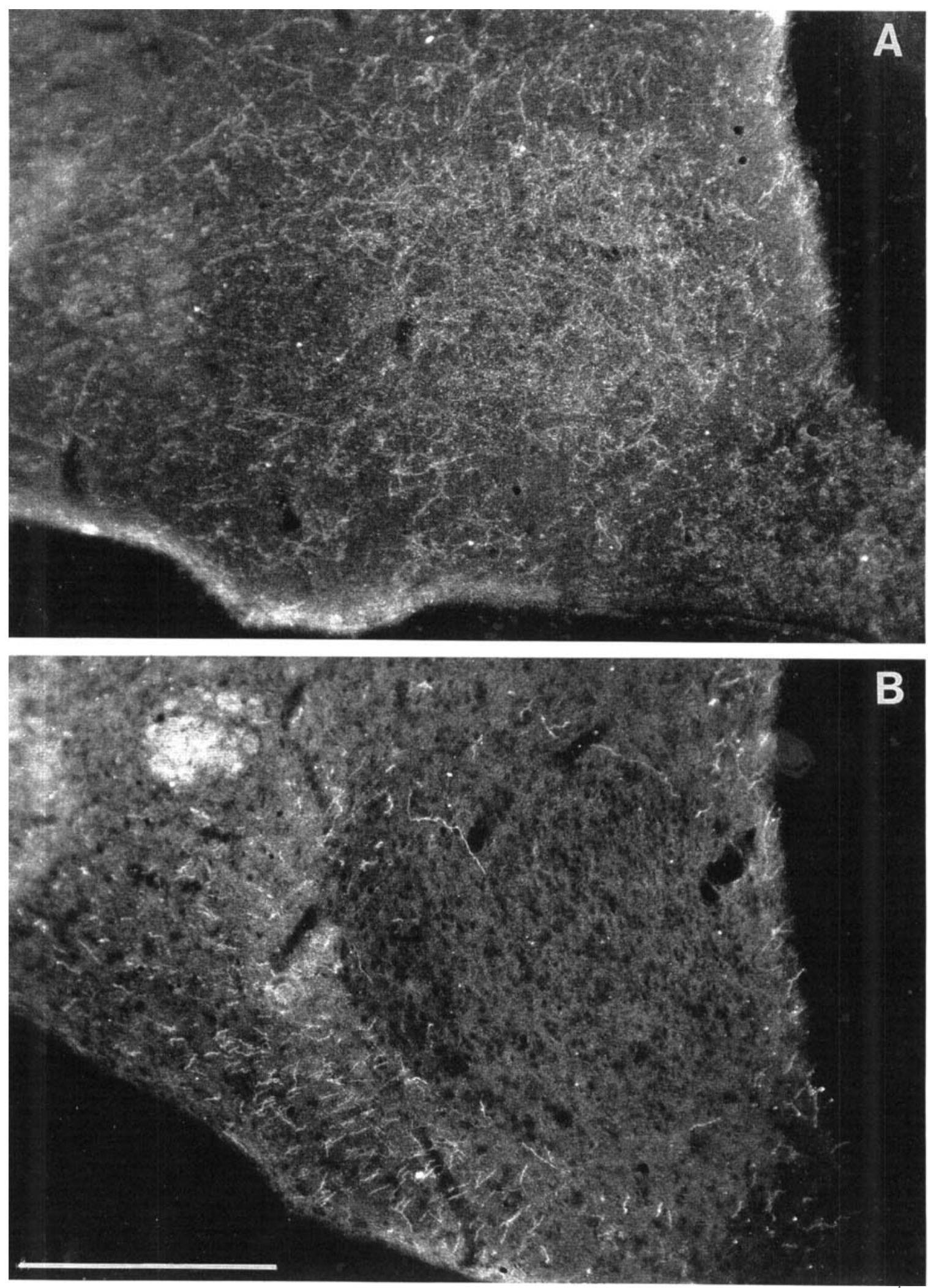

Fig. 10. Darkfield photomicrographs of PHA-L-labeled fibers in the ventromedial nucleus of the hypothalamus. Fibers were concentrated within the core of this nucleus after injections in MeA (A; $\mathrm{PH}-106)$, whereas fibers were absent in the core and present within the shell after injections in MeP (B; PH-59). Scale bar $=500 \mu \mathrm{m}$. 

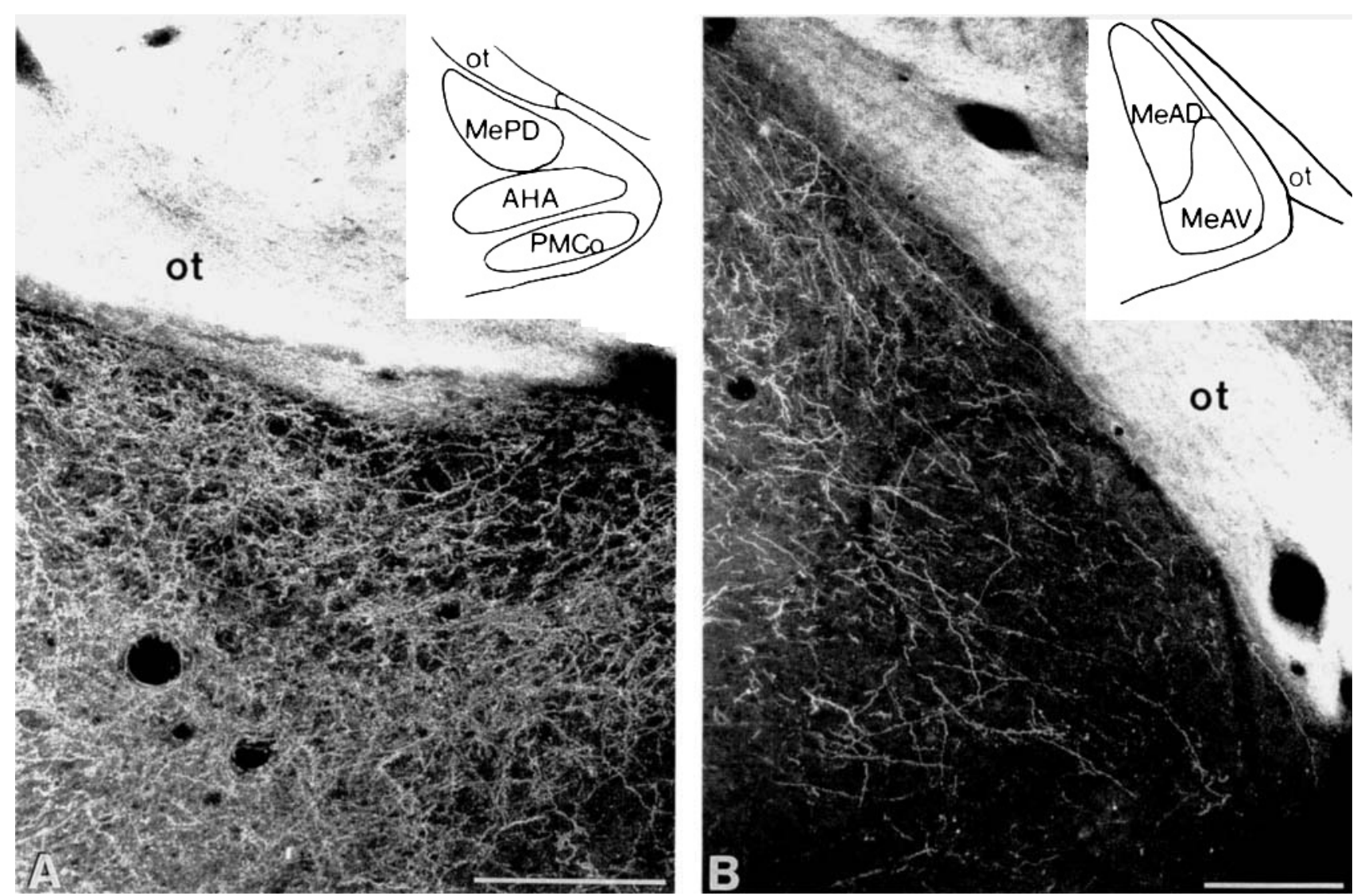

Fig. 11. Darkfield photomicrograph of PHA-L fibers in A) MeP after injections in MeA (PH-54) and B) MeA after injections in MeP $(\mathrm{PH}-59)$. Scale bar $=200 \mu \mathrm{m}$.

immediately lateral to the stria medullaris and fornix as shown in Figures $8 \mathrm{C}, \mathrm{D}$ and $12 \mathrm{C}$. This posteromedial division (Fig. 6B) is referred to as the principle part of the bed nucleus by Ju and Swanson ('89), as the posteromedial part by Moga et al. ('89), as the encapsulated part by Simerly and Swanson ('86, '88), and as the anteromedial cell column of the posteromedial subdivision of the bed nucleus by De Olmos et al. ('85) in the rat. The more caudal, preoptic part of the posteromedial bed nucleus of the stria terminalis (Fig. 6C) also received numerous afferents from MeP (Fig. 12D). In addition, unbranched fibers coursed ventromedially throughout the posteromedial bed nucleus of the stria terminalis (Fig. 12A-D), presumably on route to the preoptic extension of the bed nucleus of the stria terminalis, the medial preoptic nucleus, and more caudal targets.

Both the medial preoptic nucleus and the adjacent medial part of the medial preoptic area received heavy fiber and terminal labeling (Fig. 12B-D). At the level of the anterior commissure, axonal varicosities and endings were primarily concentrated in the medial preoptic nucleus (Fig. 12B). A few fibers were also observed in this same region contralaterally. At this level, fibers in the dorsal aspect of the medial preoptic area were predominantly strial fibers that appeared to be coursing caudal and ventral through this area. The area dorsal to the medial preoptic nucleus received greater input from MeP further caudally (Fig. 12C), and the target areas of these inputs were distinctly more medial than those which received the efferents of MeA (Fig. 10). At the level of the caudal medial preoptic area and medial preoptic nucleus, strial fibers travelling through the medial preoptic area and ventral amygdalofugal fibers heading towards the preoptic division of the bed nucleus of the stria terminalis are shown in Figure 12B-D.

Surrounding the third ventricle, numerous fibers and axonal endings were spread bilaterally from the rostral periventricular preoptic area (not designated on Fig. 12) through the periventricular nucleus of the hypothalamus (Fig. 12B-H).

A major hypothalamic target area of the $\mathrm{MeP}$ was the shell of the ventromedial nucleus of the hypothalamus. Terminals were most numerous in the lateral part of the shell. A few fibers were also noted in these same areas contralaterally. In striking contrast to the terminal labelling observed after injections in $\mathrm{MeA}$, the core of the ventromedial nucleus was devoid of any terminals from $\mathrm{MeP}$ (Figs. 10, 12G-H). Ventral to the ventromedial hypothalamic nucleus, at the pial surface, fibers of passage were also observed.

The arcuate nucleus of the hypothalamus had a low to moderate density of fibers and terminals (Fig. 12G-I). Fibers were primarily noted on the lateral aspect of the arcuate rostrally (Fig. 12G), whereas the labeling was uniform throughout the nucleus further caudally (Fig. $12 \mathrm{H}, \mathrm{I})$. Again, a few contralateral fibers were present. 
The caudal part of the arcuate nucleus and the ventral premammillary nucleus were the caudalmost hypothalamic targets of the MeP (Fig. 12I). The ventral premammillary nucleus contained dense labeling of terminals ipsilaterally, whereas only a few terminals were found in contralateral ventral premammillary nucleus.

The remaining projections of $\mathrm{MeP}$ were identified within the amygdala and amygdalohippocampal area. Terminal projections from $\mathrm{MeP}$ to MeA were numerous (Figs. 12E,F, $11 \mathrm{~B})$. In addition to this direct rostral projection, $\mathrm{MeP}$ projected caudally to the amygdalohippocampal area (Fig. $12 \mathrm{H}, \mathrm{I})$. Fibers in the anterior amygdaloid area appeared to be directed towards the ventral amygdalofugal pathway, although few varicosities and terminals were present (Fig. 12E). The anterior cortical, posteromedial cortical and intercalated mass also contained few fibers and terminals (Fig. 12F-I).

\section{DISCUSSION}

The subdivisions of the medial nucleus of the amygdala (Me) display heterogeneity in cytoarchitecture, cell morphology, neurotransmitter content, and function (Lehman et al., '80; Neal et al., '89; Neal and Newman, '91a; Gomez and Newman, '91a). Previous hodological studies of this nucleus have also suggested, but not confirmed, differences in the efferent targets of the subregions of $\mathrm{Me}$ (Leonard and Scott, '72; Krettek and Price, '78a,b; Kevetter and Winans, '81a; Luiten et al., '83). In the present study, novel and discrete projections of the anterior and posterior parts of Me have been identified. The results described for MePD confirm that projections from this area are limited to the vomeronasal circuitry, whereas the projections of MeA include both vomeronasal and olfactory circuitry. Analysis of the efferents of ventral $\mathrm{Me}$ in this study was limited to one case, in which the injection site was confined to MeAV and the projections were similar to, but not as extensive as, those described for MeAD. Although no cases had injections sites strictly confined to MePV, the trajectory of neurons from injections sites, which included both MePD and MePV compared to those from MePD alone, did not suggest separate target areas.

Unlike the techniques used in previous studies of this nucleus, in the PHA-L material analyzed here, terminal fibers were clearly distinguishable from fibers of passage and areas that did not contain an extensive terminal field were easily identified. Although anterograde transport of PHA-L may be solely attributable to distinctly filled cells at the injection site, a more conservative estimate of the injection site was made in this material to ensure that any identified targets were specific to the intended injection site. Thus, in this study, the areas that contained diffuse immunoreactivity surrounding the labeled neurons were also reported as part of the site.

\section{Chemosensory, thalamic, and ventral striatopallidal connections of $\mathrm{MeAD}$}

Connections with the chemosensory system. In 1985 , De Olmos et al. characterized the anterior amygdaloid area and the rostral tip of $\mathrm{Me}$ as nuclei belonging to the "olfactory amygdala," although Me has been associated in other studies primarily with the vomeronasal system (Scalia and Winans, '75; Kevetter and Winans, '81a; Lehman et al., '82). The MeA is perhaps best characterized as a nodal point for both olfactory and vomeronasal systems, since it receives direct input from both the main and accessory olfactory bulbs (Scalia and Winans, '75; Lehman et al., ' 82 ). Although, nuclei in the olfactory and vomeronasal systems have been shown to reciprocate inputs back to the main and accessory olfactory bulbs, respectively. In the present study, MeAD was found to project to the accessory olfactory bulb but not to the main olfactory bulb in the hamster. Thus, it does not entirely fulfill De Olmos' criteria of "olfactory amygdala" (De Olmos et al., '78; Haberly and Price, '78). Nonetheless, Me did give rise to connections to other olfactory-related areas, such as the medial and ventral parts of the anterior olfactory nucleus and the endopiriform nucleus. These projections of Me have not been identified previously. The endopiriform nucleus is an important relay of olfactory information to the diencephalon and ventral forebrain (Switzer et al., '85) and has projections to these targets similar to those described here for MeAD (Haberly and Price, '78; Switzer et al., ' 85 ).

The course of these olfactory target projections from MeA appears to be primarily through the rostral extension of the ventral amygdalofugal system of De Olmos ('72). This pathway is present along the ventromedial surface of the brain where many PHA-L fibers were observed. In lesion and degeneration studies, De Olmos ('72) described the terminal fields of this ventral pathway in the same parts of the anterior olfactory nucleus and olfactory tubercle as those described here for the efferents of $\mathrm{MeAD}$.

Since MeA receives vomeronasal and olfactory inputs from the accessory and main olfactory bulbs (Lehman and Winans, ' 82 ), and because both of these regions relay back to the accessory olfactory bulb and to olfactory structures, MeA may be considered as an integration area for these systems, or the "chemosensory amygdala." Owing to the lack of direct olfactory afferents to MeP or efferent projections to olfactory-related structures, $\mathrm{MeP}$ is more appropriately associated strictly with the "vomeronasal amygdala" along with the posteromedial cortical nucleus.

Connections with the thalamus. Thalamic afferents from $\mathrm{MeAD}$ formed a continuum of terminals along the medial edge of the mediodorsal nucleus and within the midline thalamic nuclei: the paraventricular and parataenial nuclei, nucleus reuniens, and the lateral habenula of the epithalamus, similar to those previously described in the rat (Siegel et al., '77). Most of these thalamic nuclei have been associated with the chemosensory system in the rodent (Ottersen and Ben Ari, '79). The anterior cortical and posterolateral cortical nuclei of the amygdala, both of which are recipients of olfactory bulb inputs (Scalia and Winans, '75; Lehman et al., '82) receive inputs from various midline thalamic nuclei (De Olmos et al., '85). These studies suggest that these thalamic connections may be involved in processing olfactory information within the chemosensory system. Therefore, in light of the findings of the present study, it is not surprising that MeAD is a source of inputs to these nuclei. Projections from $\mathrm{MeP}$ to the thalamus were not observed. Amygdaloid fibers reach their thalamic targets by two routes: 1 ) fibers within the stria terminalis exit and travel medially to enter the stria medullaris and thence to the thalamic nuclei, or 2) fibers course dorsomedially through the ventral amygdalofugal pathway to terminate in reuniens and pass through the centromedial and rhomboid nuclei to innervate the dorsal midline thalamic nuclei. Although, both of these routes have been suggested for 

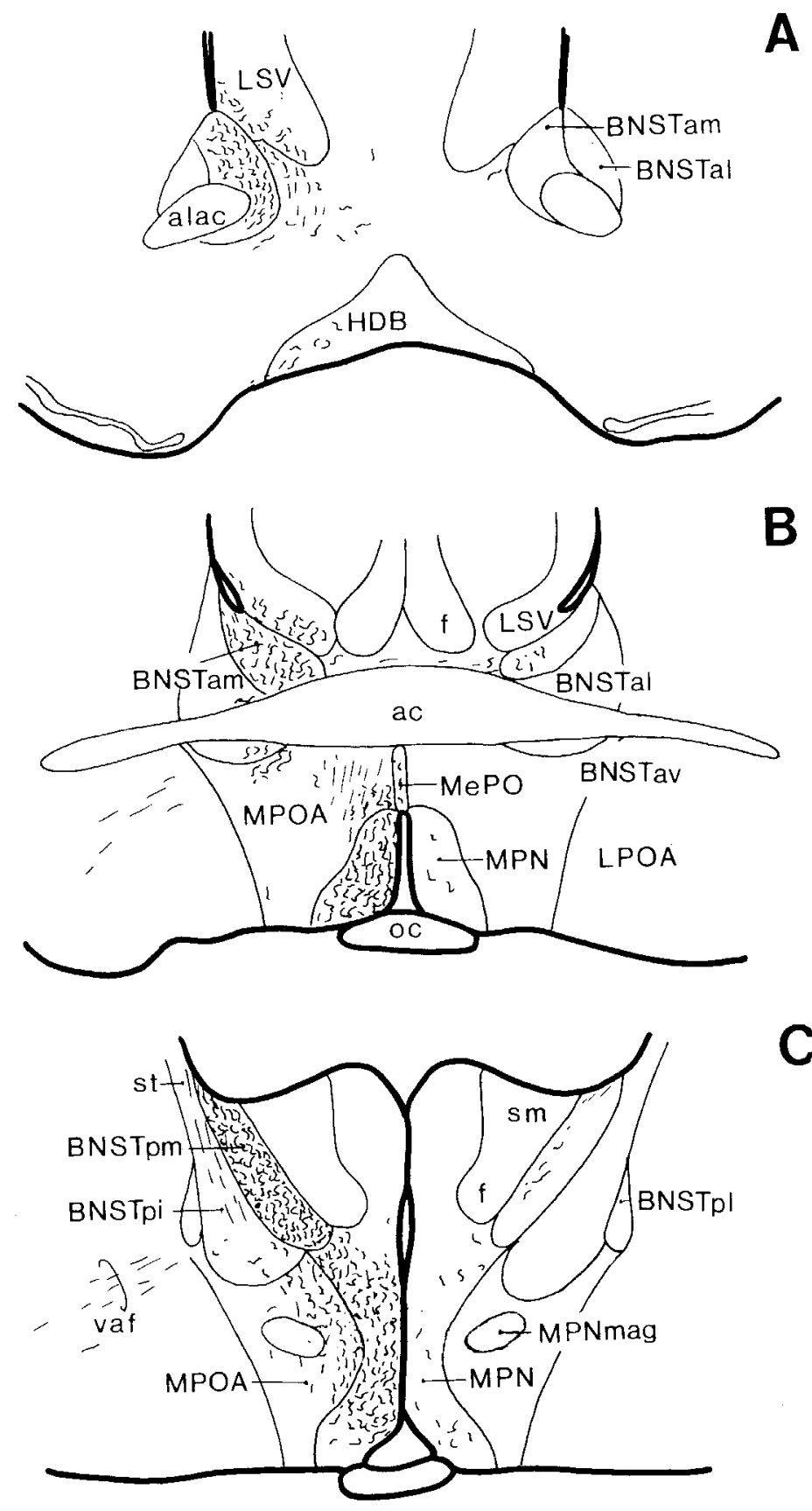

C

D

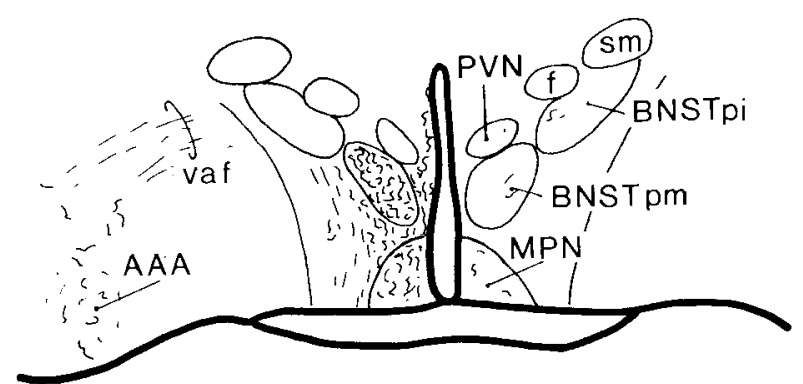

Fig. 12. Schematic drawings (A-I) of the distribution of fibers throughout the forebrain after injections of PHA-L confined to MeP in animal PH-59. Short curved lines represent terminal fields whereas straight lines represent axons of passage. 


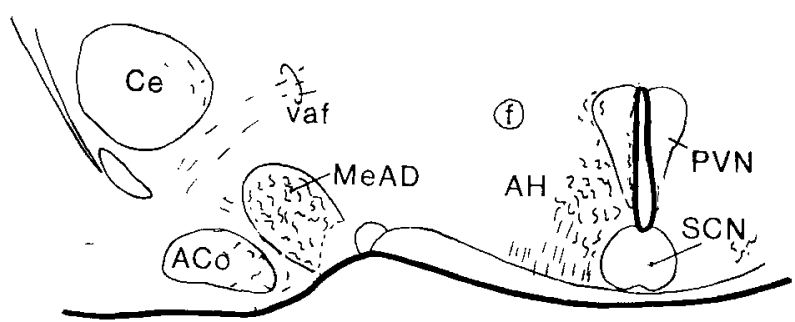

$\mathbf{E}$
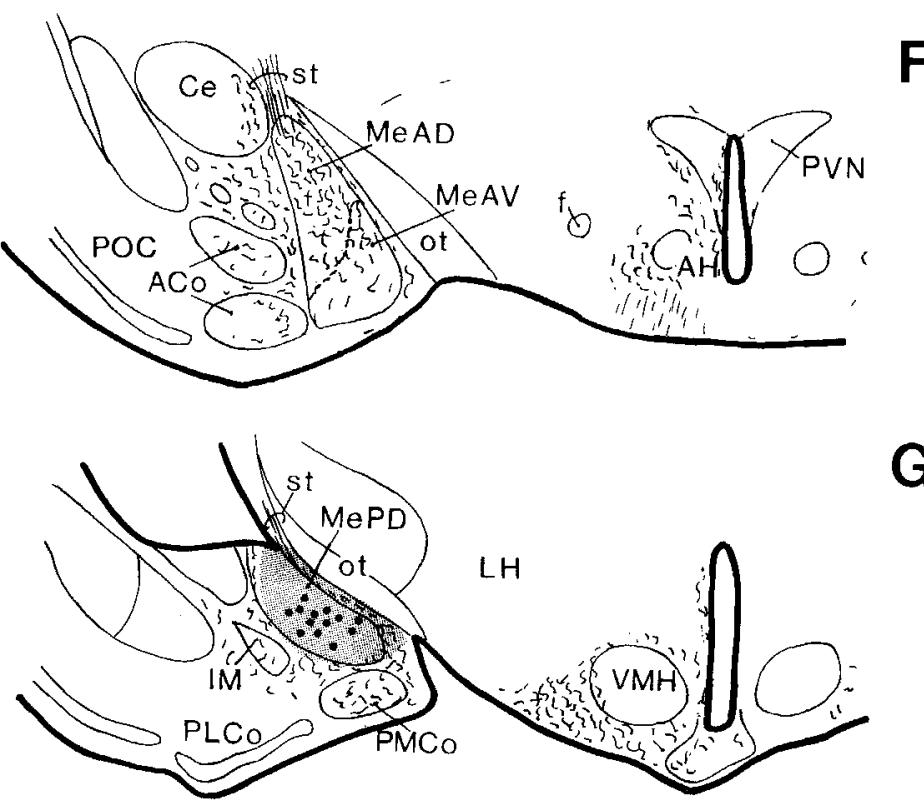

G

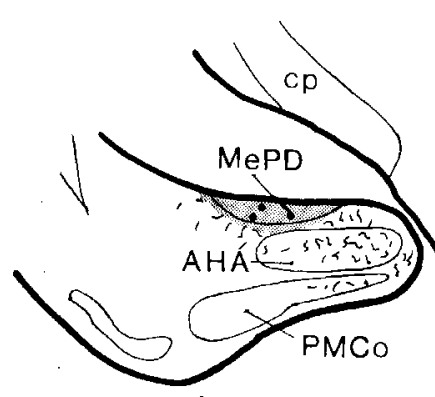

H

F

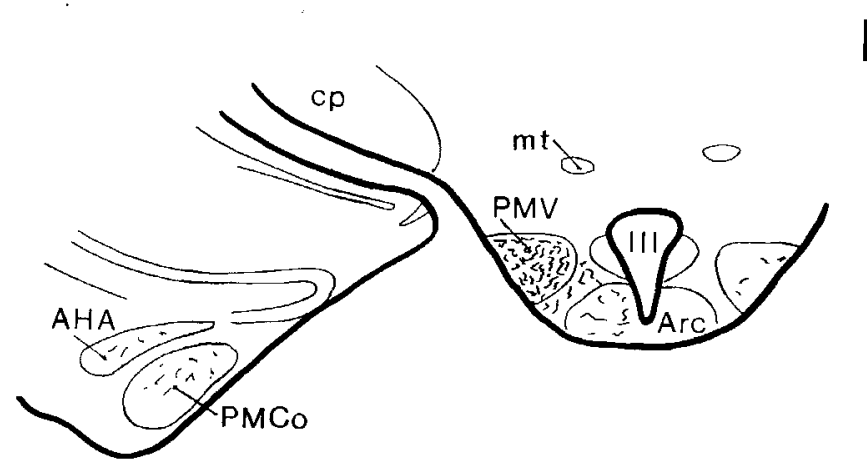

Fig. 12 continued 
other amygdaloid trajectories, they have not been described for those from Me to the thalamus (De Olmos, '72).

Connections with ventral striatopallidal system. The $\mathrm{MeAD}$ also appears to be closely associated with the ventral striatopallidal system. Work from several laboratories has demonstrated that the ventral striatum and pallidum are associated with the amygdala (Heimer et al., '85; Price et al., '87; Alheid and Heimer, '88). Amygdalostriatal projections to nucleus accumbens and the olfactory tubercle have been found to originate in the lateral, basolateral, and basomedial amygdaloid nuclei of the rat (Kelley et al., '82). In the hamster, the basolateral nucleus also projects to nucleus accumbens and the basolateral, basomedial, anterior cortical, and posterolateral cortical nuclei to the olfactory tubercle (Newman and Winans, '80a, '80b; Kevetter and Winans, '81b; Zaborsky et al., '85). The projections from $\mathrm{MeAD}$ into the ventral striatopallidal complex (specifically the ventral pallidum rostrally, the fundus striati, the shell of nucleus accumbens, and the medial olfactory tubercle) in the hamster are reported here for the first time. A retrograde tract-tracing study (Newman and Winans, '80a), which injected HRP into nucleus accumbens of the hamster, did not reveal afferent input from $\mathrm{Me}$ seen in this report. The centers of the HRP injection sites in this HRP study, however, were confined to the core of nucleus accumbens and would therefore have failed to confirm the projection of MeA into the shell of nucleus accumbens. The medial and central amygdaloid nuclei, on the other hand, have been associated with regions of substantia innominata (Grove, '88a,b) and these connections have been designated as part of the "extended amygdala" (Alheid and Heimer, '88), and it appears that the connections observed in this report from MeAD to the sublenticular substantia innominata may be connections from additional subregions of this "extended amygdala" to the ventral striatopallidal system. The outflow of chemosensory information to these areas may be important in integrating olfactory and vomeronasal motivated behaviors, such as copulatory behavior, with control of corresponding somatomotor responses.

\section{Bed nucleus, preoptic, hypothalamic, and amygdaloid connections of MeAD and MePD}

The projections of the medial amygdaloid nucleus to the bed nucleus of the stria terminalis, preoptic area, and hypothalamus have been well established (De Olmos et al., '72, '85; McBride and Sutin, '77; Krettek and Price, '78a; Kevetter and Winans, '81a; Weller and Smith, '82; Lehman and Winans, '83; Simerly and Swanson, '86, '87, '88; Maragos et al., '89; Perez-Clausell, '89); however the results of the present study suggest that the inputs of MeAD and MeAV to the bed nucleus, preoptic area, and the ventromedial nucleus of the hypothalamus are distinctly different from those of MePD. In contrast to these differences, MeAD, MeAV, and MePD had indistinguishable patterns of inputs to the paraventricular, periventricular, arcuate and ventral premammillary nuclei of the hypothalamus, and to the ventral part of the lateral septum.

Connections with the bed nucleus of the stria terminalis. In the hamster, $\mathrm{MeAD}, \mathrm{MeAV}$, and $\mathrm{MePD}$ all projected to the anteromedial division and the medial part of the anteroventral division of the bed nucleus, but at the caudal boundary of the anterior commissure, striking differences between the terminal targets of these amygdaloid nuclei were observed within the posterior bed nucleus. Both subdivisions of the MeA projected to the posterointermedial part of the bed nucleus (also suggested by Weller and Smith, '82), whereas MePD projected to the posteromedial part of the bed nucleus at this level. This differential innervation of the bed nucleus from $\mathrm{MeA}$ and $\mathrm{MeP}$ had also been suggested by Leonard and Scott ('71). Krettek and Price ('78b) did not distinguish differences between the efferents of MeA and MeP. However, they did observe a medial versus intermediate topography for anterior and posterior amygdaloid projections to the posteromedial bed nucleus of the stria terminalis. These investigators identified projections from the posteromedial cortical amygdaloid nucleus (their posterior cortical nucleus) and amygdalohippocampal area that were similar to our MePD projections to the medial part of the posteromedial bed nucleus. In this study, inputs from $\mathrm{Me}$ to the posterointermedial bed nucleus (as defined here) were similar to MeA projections we observed in the hamster.

The medial nucleus has been reported to have reciprocal connections with the bed nucleus in the hamster by Damlama and Swann ('90) and in the rat by Swanson and Cowan ('76); however the data in the rat suggest that the posteromedial region of the bed nucleus projects predominantly to $\mathrm{MeA}$, whereas the anterior bed nucleus innervates only MeP. If this pattern is also true in hamster, then the connections are not truly reciprocal. The functional importance of these connections is discussed further below.

The pathways that provide Me inputs to the bed nucleus of the stria terminalis are primarily strial (De Olmos, ' 72 ; Kevetter and Winans, '81a), and many PHA-L-labeled fibers in this study were found within the medial part of the stria terminalis. In the hamster, the strial efferents of $\mathrm{MeA}$ were seen primarily in the ventral component of the medial stria terminalis. This is consistent with labeling after injections of tritiated amino acid into $\mathrm{Me}$ in the hamster (Kevetter and Winans, '81a) and observations in the rat that lesions of the ventromedial component of the stria terminalis produced terminal degeneration within the posterolateral (our posterointermedial) bed nucleus, as well as other MeA targets in the hypothalamus (De Olmos, '72). The strial efferents of MeP to the bed nucleus, on the other hand, course primarily through the dorsomedial component of this pathway in the hamster (Maragos et al., '89) and the rat (De Olmos, '72). Kevetter and Winans ('81a) observed labeling in this part of the stria terminalis after injections into the posteromedial cortical nucleus, also part of the vomeronasal amygdala. In the present study, many labeled fibers were also observed in the ventral amygdalofugal pathway from $\mathrm{MeA}$ and $\mathrm{MeP}$ coursing dorsomedially towards the posterior and preoptic areas of the bed nucleus (Lehman and Winans, '83).

Connections with the preoptic area. Projections of $\mathrm{Me}$ to the medial preoptic area and anterior hypothalamus have been observed in numerous studies (Krettek and Price, '78; Kevetter and Winans, '81a; Berk and Finkelstein, '81; Maragos et al., '89; Neal et al., '89; Neal and Newman, '91a). In addition, many parts of the preoptic area and hypothalamus have reciprocal projections to Me (Kreiger et al., '79; Ottersen, '80; Swanson, '87; Conrad and Pfaff, '75, '76). These studies present evidence that the medial preoptic area, anterior hypothalamus, paraventricular, periventricular, ventromedial, dorsomedial, ventral premammillary, dorsal premammillary, and arcuate nuclei of the hypothalamus receive inputs from the different parts of the amygdala investigated here. Specifically, MePD has been 
shown to be the primary source of these projections. This supports our observation of a preferential distribution of MePD fibers within the medial part of the medial preoptic area, in the medial preoptic nucleus, and in the anterior hypothalamic area. Although MeA provide afferents to the medial preoptic area (Krettek and Price, '78; Kevetter and Winans, '81a; Berk and Finkelstein, '82; Simerly and Swanson, '88), this projection, in our material, was concentrated laterally within this region. Maragos et al. ('89) observed a majority of the neurons in MePD after the retrograde tracer HRP was deposited in the medial part of the medial preoptic area, but neurons were found rostral to $\mathrm{MeP}$ when this tracer was injected laterally within the perifornical area. Injections in MeA also produced fiber labeling in the lateral preoptic area, lateral hypothalamus, and lateral tuberal area and were consistent with similar connections previously described in the rat (Krettek and Price, '78a; Berk and Finkelstein, '82).

Connections with the ventromedial nucleus of the hypothalamus. The dorsomedial and ventromedial nuclei of the hypothalamus have been implicated in many physiological responses, such as feeding and female sexual behavior (Swanson, '87; Pfaff, ' 80 ). The connections from olfactory and vomeronasal systems with these areas is therefore not surprising. However, this investigation has clarified, at least in the hamster, separate connections from neurons in $\mathrm{MeA}$ to the core, and from MeP neurons to the shell of the ventromedial nucleus. These projections are bilateral. Several previous reports have also identified Me inputs to the core of this nucleus from MeA (DeOlmos, '72; McBride and Sutin, '77; Berk and Finkestein, '82; Luiten et al., '83). In the rat, Krettek and Price ('78) observed projections from Me to the core. It is possible that the injection sites in their study were primarily in the rostral part of Me. Luiten et al. ('83) injected horseradish peroxidase into the ventromedial nucleus and identified differential projections from $\mathrm{MeA}$ to the dorsomedial part of this nucleus (or the hamster equivalent of the medial and perhaps central parts of the core), whereas MeP had projections to both core and shell. Canteras et al. ('89), however, did observe MeP projections into the shell of the ventromedial nucleus in the rat.

Interestingly, the $\mathrm{MeP}$ connections to the shell of the ventromedial nucleus corresponds to an area that contains a large population of gonadal steroid-accumulating neurons in the hamster (Krieger et al., '76). Thus the steroidconcentrating regions of this system appear to be interconnected as has been observed in other systems (Simerly and Swanson, '86; Canteras et al., '89). Through this circuitry integrated vomeronasal and hormonal information may control female sexual behavior (Pfaff, '80).

Connections with other hypothalamic areas. In contrast to these medial versus lateral projections to the bed nucleus and preoptic area, or the shell versus core projections to the ventromedial nucleus of the hypothalamus, several important limbic areas received comparable inputs from $\mathrm{MeA}$ and MeP. Examples are the ventral premammillary nucleus, arcuate, periventricular, and the area surrounding the paraventricular nuclei of the hypothalamus. The Me inputs to these hypothalamic nuclei are in agreement with previous studies (Kevetter and Winans, '81a; Krettek and Price, '78a; De Olmos et al., '85).

Connections with the lateral septum. Several observations in the literature link the ventral part of the lateral septum with the olfactory and vomeronasal pathways through the amygdala. In this study, the ventral lateral septum received inputs from $\mathrm{MeA}$ and $\mathrm{MeP}$ and thus may receive both olfactory and vomeronasal inputs. In the rat, these inputs from Me have been shown to contain vasopressin and to project, at least in part, through the ventral amygdalofugal pathway (Caffe et al., '87). This part of the lateral septum also receives afferents from the amygdalalohippocampal area and the posteromedial cortical nucleus (Krettek and Price, '78a), amygdaloid nuclei that belong to the vomeronasal circuitry. The ventral lateral septum, in turn, projects to the medial preoptic area and anterior hypothalamus (Swanson and Cowan, '76). In addition, many neurons of the ventral lateral septum accumulate gonadal steroids (Krieger et al., '76; Doherty and Sheridan, '81). Taken together, these observations suggest a possible role for the ventral lateral septum in male reproduction and related social behaviors. This notion is supported by Irwin et al. ('90) who have demonstrated specific changes in flank marking behavior in male hamsters following microinjections of arginine vasopressin into this region of the brain.

Efferents of MeA, but not MeP, were also found in the dorsal and more heavily in the intermediate parts of the lateral septum. This is an indirect route for $\mathrm{MeA}$ to innervate the diagonal band, lateral preoptic area, and lateral hypothalamus, since the dorsal and intermediate parts of the lateral septum are known to have projections into these territories (Swanson and Cowan, '76).

Intra-amygdaloid connections. Most but not all of the intra-amygdaloid projections identified in the hamster had also been previously observed. Among the olfactory-related targets (Kevetter and Winans, ' $81 \mathrm{~b}$ ), both parts of Me project to the anterior cortical and posterolateral cortical nuclei. MeA alone projects to the nucleus of the lateral olfactory tract. Vomeronasal targets of the amygdala ("vomeronasal amygdala" of Kevetter and Winans, '81a), which receive inputs from the accessory olfactory bulb, also receive inputs from $\mathrm{MeA}$ and $\mathrm{MeP}$. These structures include the posteromedial cortical nucleus, the amygdalohippocampal area, and the nucleus of the accessory olfactory tract. Furthermore, MeA and MeP, both of which also had been considered as part of the vomeronasal system, reciprocate connections to each other. This finding had also been previously reported in the rat (De Olmos, '72). The projections from MeA to MeP may relay integrated olfactory and vomeronasal information critical to $\mathrm{MeP}$ regulation of the temporal pattern of mating behavior (Lehman et al., '83). The intra-amygdaloid connections of MeA are more extensive than those of $\mathrm{MeP}$. The inputs to the basomedial, intra-amygdaloid bed nucleus of the stria terminalis, posterolateral cortical, and posterior basolateral nuclei were primarily from MeA (Ottersen, '82; De Olmos et al., '85).

\section{Implications for male reproductive behavior}

$\mathrm{MeA}$ receives both olfactory and vomeronasal information from the olfactory bulbs and is critical to the control of normal copulatory behavior in the male hamster (Lehman et al., ' 80, ' 82 ). MeP, in contrast, receives direct input only from the vomeronasal system (Lehman et al., '82) and appears to modulate the temporal pattern of copulatory behavior in the hamster (Lehman et al., '83). In addition, this posterior region contains a dense population of androgen accumulating neurons (Doherty and Sheridan, '81; Simerly et al., '90; unpublished observations), which are structurally and neurochemically responsive to changes in 
circulating gonadal steroids (Malsbury et al., '87; Simerly and Swanson, '87; Swann and Newman, '87; Gomez and Newman, '91b). We have hypothesized that three signals, vomeronasal, olfactory, and hormonal, are integrated along the chemosensory pathway in order for copulatory behavior to occur. Both regions of Me each receive two of the three necessary inputs; $\mathrm{MeA}$ receives both vomeronasal and olfactory inputs, whereas $\mathrm{MeP}$ receives vomeronasal and hormonal inputs. The results of the present study suggest two possible routes by which all three signals can be integrated. First, a direct projection from MeA to MeP has been demonstrated. Thus, it would appear that all three signals may be integrated in $\mathrm{MeP}$ and relayed from there to the posteromedial bed nucleus of the stria terminalis and the medial preoptic area, both of which are important for the display of normal copulatory behavior in the hamster. However, as noted above, the results of lesion studies suggest that $\mathrm{MeP}$ regulates, but is not critical to, the control of male reproductive behavior in this species (Lehman et al., '82, '83). A second route by which olfactory, vomeronasal, and hormonal signals are integrated might therefore be from MeA directly to the hormone-uptake regions of the bed nucleus and preoptic area. The results of this report, however, does not demonstrate such projections, but rather shows that MeA projects primarily to the posterointermediate part of the bed nucleus, the lateral part of the medial preoptic area, and to the hypothalamus, territories that contain fewer steroid-accumulating neurons and that have not been implicated in controlling male hamster sexual behavior. It is possible that intranuclear projections from the intermediate to the medial parts of the bed nucleus and preoptic areas exist similar to the intranuclear projections within Me. A projection from the lateral preoptic area to the medial preoptic area has been observed in the hamster (Neal and Newman, '91b). This would provide the chemosensory inputs to the gonadal steroiduptake areas that control mating behavior.

These connections are consistent with the functional studies of these areas. Lesions along the border between the medial and intermediate parts of the posterior bed nucleus produced deficits in chemoinvestigatory behavior that normally precedes copulatory behavior (Powers et al., '87). Damage to the region lateral to the medial preoptic nucleus eliminated copulatory behavior (Powers et al., '87). These areas may disrupt the interconnections of the chemosensory circuit from MeA and the gonadal steroid circuit from $\mathrm{MeP}$ and remove the integration of these signals that are necessary to drive these reproductive behaviors.

An alternate hypothesis proposes that all three signals are in fact integrated in MeA. To support this notion, it is important to consider some of the afferents of MeA in light of this circuitry. Since studies in the rat have demonstrated inputs to MeA from the steroid uptake areas of the posteromedial bed nucleus (Swanson and Cowan, '76), the medial preoptic area (personal communication, J. Morrell), and MeP (present results), it is therefore possible that MeA itself is critical for normal copulatory behavior, not only because lesions of this area eliminate mating behavior but because it receives the third required component for this behavior, gonadal steroids, from other steroid-sensitive areas. Therefore, gonadal steroid feedback from any one of these hormone-accumulating regions may be integrated with the essential chemosensory information received within MeA.

In summary, the differential projections of $\mathrm{MeA}$ and $\mathrm{MeP}$ suggest that the integration of the "chemosensory amygdala" with the vomeronasal circuitry and steroidsensitive regions of the brain may form the underlying substrate for male reproductive behavior in the hamster. Furthermore, the trajectories of the chemosensory areas with other areas outside the vomeronasal circuitry may be essential for coordinating olfactory and pheromonally guided social behaviors with the corresponding motor responses for normal reproductive behavior.

\section{ACKNOWLEDGMENTS}

The authors wish to thank Drs. Jennifer Swann and Anthony Kincaid for their helpful comments on this manuscript. This research was supported by NIH Grant NS20629 to SWN.

\section{LITERATURE CITED}

Alheid, G.F., and L. Heimer (1988) New perspectives in basal forebrain organization of special relevance for neuropsychiatric disorders: The striatopallidal, amygdaloid, and corticopetal components of substantia innominata. Neuroscience 27:1-39.

Berk, M.L., and J.A. Finkelstein (1981) Afferent projections to the preoptic area and hypothalamic regions in the rat brain. Neuroscience 6:16011624.

Berk, M.L., and J.A. Finkelstein (1982) Efferent connections of the lateral hypothalamic area of the rat: An autoradiographic investigation. Brain Res. Bull. 8:511-526.

Caffe, A.R., F.W. van Leeuwen, and P.G.M. Luiten (1987) Vasopressin cells in the medial amygdala of the rat project to the lateral septum and ventral hippocampus. J. Comp. Neurol. 261:237-252.

Canteras, N.S., R.B. Simerly, and L.W. Swanson (1989) The efferent connections of the amygdalo-hippocampal area: A Phaseolus vulgaris leucoaghtinin tract-tracing study in the rat. Soc. Neurosci. 15:498.17.

Conrad, L.C.A., and D.W. Pfaff (1975) Axonal projections of medial preoptic and anterior hypothalamic neurons. Science 190:1112-1113.

Conrad, L.C.A., and D.W. Pfaff (1976) Efferents from medial basal forebrain and hypothalamus in the rat. II. an autoradiographic study of the anterior hypothalamus. J. Comp. Neurol. 169:221-262.

Damlama, M., and J.M. Swann (1990) The efferent projections of the bed nucleus of the stria terminalis in the syrian hamster. Soc. Neurosci. 16:103.

De Olmos, J.S. (1972) The amygdaloid projection field in the rat as studied with cupric-silver method. In B.E. Eleftheriou (ed): The Neurobiology of the Amygdala. New York: Plenum Press. pp. 145-204.

De Olmos, J., H. Hardy, and L. Heimer (1978) The afferent connections of the main and accessory olfactory bulb formations in the rat: an experimental HRP-study. J. Comp. Neurol. 181:213-244.

De Olmos, J., G.F. Alheid and C.A. Beltramino (1985) Amygdala. In G. Paxinos (ed): The Rat Nervous System. New York: Academic Press. pp. 223-334.

De Vries, G.J., R.M. Buijs, F.W. Van Leeuwen, A.R. Caffe, and D.F. Swaab (1985) The vasopressinergic innervation of the brain in normal and castrated rats. J. Comp. Neurol. 233:236-254.

Doherty, P.C., and Sheridan, P. (1981) Uptake and retention of androgens in neurons of the brain of the golden hamster. Brain Res. 219:327-334.

Dornan, W.A., and C.W. Malsbury (1989) Neuropeptides and male sexual behavior. Neurosci. Biobehav. Rev. 13:1-15.

Gomez, D.M. (1991a) Doctoral Dissertation, University of Michigan. The Cytoarchitecture, Neuronal Morphology and Connections of the Medial Amygdaloid Nucleus and the Influence of Gonadal Steroids on Neuronal Structure in the Adult Male Syrian Hamster. pp. 24-79.

Gomez, D.M., and S. Winans Newman (1991b) Medial nucleus of the amygdala in the syrian hamster: A quantitative golgi analysis of gonadal hormone regulation of neuronal morphology. Anat. Rec. in press. 
Grove, E.A. (1988a) Neural associations of the substantia innominata in the rat: Afferent connections. J. Comp. Neurol. 277:315-346.

Grove, E.A. (1988b) Efferent connections of the substantia innominata in the rat. J. Comp. Neurol. 277:347-364.

Haberly, L.B., and J.L. Price (1978) Association and commissural fiber systems of the olfactory cortex of the rat. I. Systems originating in the piriform cortex and adjacent areas. J. Comp. Neurol. 178:711-740.

Heimer, L., and W.J.H. Nauta (1969) The hypothalamic distribution of the stria terminalis in the rat. Brain Res. 13:284-297.

Heimer, L., G.F. Alheid, and L. Zaborszky (1985) Basal Ganglia. In G. Paxinos (ed): The Rat Nervous System. New York: Academic Press. pp. 37-86.

Irwin, R.W., P. Szot, D. Dorsa, and C.F. Ferris (1990) Vasopressin-sensitive neurons in the lateral septum and bed nucleus of the stria terminalis are involved in the control of flank marking behavior in golden hamsters. Soc. Neurosci. 15:1070.

Ju, G., and L.W. Swanson (1989) Studies on the cellular architecture of the bed nucleus of the stria terminalis in the rat. 1. Cytoarchitecture. J. Comp. Neurol. 280:587-602.

Kelley, A.E., V.B. Domesick, and W.J.H. Nauta (1982) The amygdalostriatal projection in the rat: An anatomical study by anterograde and retrograde tracing methods. Neuroscience 7:615-630.

Kevetter, G.A., and S.S. Winans (1981a) Connections of the corticomedial amygdala in the golden hamster. I. efferents of the "vomeronasal amygdala." J. Comp. Neurol. 197:81-98.

Kevetter, G.A., and S.S. Winans (1981b) Connections of the corticomedial amygdala in the golden hamster. II. Efferents of the "olfactory amygdala." J. Comp. Neurol. 197:99-111.

Krettek, J.E., and J.L. Price (1977) Projections from the amygdaloid complex to the cerebral cortex and thalamus in the rat and cat. J. Comp. Neurol. 172:687-722.

Krettek, J.E., and J.L. Price (1978a) Amygdaloid projections to subcortical structures within the basal forebrain and brainstem in the rat and cat. J. Comp. Neurol. 178:225-254.

Krettek, J.E., and J.L. Price (1978b) A description of the amygdaloid complex in the rat and cat with observations on intra-amygdaloid axonal connections. J. Comp. Neurol. 178:255-280.

Krieger, M.S., L.C.A. Conrad, and D.W. Pfaff (1979) An autoradiographic study of the efferent connections of the ventromedial nucleus of the hypothalamus. J. Comp. Neurol. 183:785-816.

Krieger, M.S., J.L. Morrell, and D.W. Pfaff (1976) Autoradiographic localization of estradiol-concentrating cells in the female hamster brain. Neuroendocrinology 22:193-205.

Lehman, M.N., J.B. Powers, and S.S. Winans (1980) Medial nucleus of the amygdala mediates chemosensory control of male hamster sexual behav ior. Science 210:557-560.

Lehman, M.N. (1982) Doctoral dissertation: University of Michigan. Amygdaloid efferents to the bed nucleus of the stria terminalis and the medial preoptic-anterior hypothalamic area controlling male hamster sexual behavior: Behavioral and HRP analysis. pp. 110-154

Lehman, M.N., S.S. Winans, and J.B. Powers (1982) Vomeronasal and olfactory pathways to the amygdala controlling male hamster sexual behavior: Autoradiographic and behavioral analyses. Brain Res. 240:27 41.

Lehman, M.N., and S.S. Winans (1983) Evidence for a non-strial pathway from the amygdala to the bed nucleus of the stria terminalis in the male golden hamster. Brain Res. 268:139-146.

Lehman, M.N., J.B. Powers, and S.S. Winans (1983) Stria terminalis lesions alter the temporal pattern of copulatory behavior in the male golden hamster. Behav. Brain Res. 8:109-128.

Leonard, C.M., and J.W. Scott (1971) Origin and distribution of the amygdalofugal pathways in the rat: an experimental neuroanatomical study. J. Comp. Neurol. 141:313-330.

Luiten, P.G.M., T. Ono, H. Nishijo, and M. Fukuda (1983) Differential input from the amygdaloid body to the ventromedial hypothalamic nucleus in the rat. Neurosci. Lett. 35:253-258.

Malsbury, C.W., K. McKay, and K. Hansen (1987) Testosterone regulates the substance $P$ innervation of the medial nucleus of the amygdala. Soc Neurosci. 13:1576.

Maragos, W.F., S.W. Newman, M.N. Lehman, and J.B. Powers (1989) Neurons of origin and fiber trajectory of amygdalofugal projections to the medial preoptic area in syrian hamsters. J. Comp. Neurol. 280:59-71.
McBride, R.L., and J. Sutin (1977) Amygdaloid and pontine projections to the ventromedial nucleus of the hypothalamus. J. Comp. Neurol 174:377-396.

Moga, M.M., C.B. Saper, and T.S. Gray (1989) Bed nucleus of the stria terminalis: Cytoarchitecture, immunocytochemistry, and projection to the parabrachial nucleus in the rat. J. Comp. Neurol. 283:315-332.

Neal, C.R., J.M. Swann, and S.W. Newman (1989) The colocalization of substance $P$ and prodynorphin immunoreactivity in neurons of the medial preoptic area, bed nucleus of the stria terminalis and media nucleus of the amygdala of the syrian hamster. Brain Res. 496:1-13.

Neal Jr., C.R., and S.W. Newman (1991a) Prodynorphin- and substance P-containing neurons project to the medial preoptic area in the male syrian hamster. Brain Res. 546:119-131.

Neal, C.R., and S.W. Newman (1991b) Proopiomelanocortin distribution in the male syrian hamster brain and beta-endorphinergic projections from the arcuate nucleus of the hypothalamus to the medial preoptic area. J. Comp. Neurol. submitted.

Newman, R., and S.S. Winans (1980a) An experimental study of the ventral striatum of the golden hamster. I. Neuronal connections of the nucleus accumbens. J. Comp. Neurol. 191:167-192.

Newman, R., and S.S. Winans (1980b) An experimental study of the ventral striatum of the golden hamster. II. Neuronal connections of the olfactory tubercle. J. Comp. Neurol. 191:193-212.

Newman, S.W., R.J. Wood, J.M. Swann, and R.K. Brabec (1991) Androgen and estrogen concentrating neurons in the medial preoptic area and the medial nucleus of the amygdala. Soc. Neurosci. 17:1411.

Ottersen, O.P., and Y. Ben-Ari (1979) Afferent connections to the amygdaloid complex of the rat and cat. 1. Projection from the thalamus. J. Comp. Neurol. 187:401-424

Ottersen, O.P. (1980) Afferent connections to the amygdaloid complex of the rat and cat. II. Afferents from the hypothalamus and the basal telencephalon. J. Comp. Neurol. 194:267-289.

Ottersen, O.P. (1982) Connections of the amygdala of the rat. IV. Corticoamygdaloid and intra-amygdaloid connections studied with axonal transport of horseradish peroxidase. J. Comp. Neurol. 205:30-48.

Paxinos, G. (1985) The Rat Nervous System, Vol. 1, Forebrain and Midbrain. New York: Academic Press.

Perez-Clausell, J., C.J. Frederickson, and G. Danscher (1989) Amygdaloid efferents through the stria terminalis in the rat give origin to zinccontaining boutons. J. Comp. Neurol. 290:201-212.

Pfaff, D.W. (1980) Estrogens and Brain Function. New York: Plenum Press.

Powers, J.B., S.W. Newman, and M.L. Bergondy (1987) MPOA and BNST lesions in the male syrian hamsters: Differential effects on copulatory and chemoinvestigatory behaviors. Behav. Brain Res. 23:181-195.

Price, J.L., F.T. Russchen, and D.G. Amaral (1987) The amygdaloid complex. In A. Bjorkland, T. Hokfelt, and L.W. Swanson (eds): Handbook of Chemical Neuroanatomy, Vol. 5, Integrated Systems of the CNS, Part I. New York: Elsevier, pp. 279-388.

Scalia, F., and S.S. Winans (1975) The differential projections of the olfactory bulb and the accessory olfactory bulb in mammals. J. Comp. Neurol. 161:31-56.

Siegel, A., T. Fukushima, R. Meibach, L. Burke, H. Edinger, and S. Weiner (1977) The origin of the afferent supply to the mediodorsal thalamic nucleus: enhancement of HRP transport by selective lesions. Brain Res. 135:11-23.

Simerly, R.B., and L.W. Swanson (1986) The organization of neural inputs to the medial preoptic nucleus of the rat. J. Comp. Neurol. 246:312-342.

Simerly, R.B., and L.W. Swanson (1987) Castration reversibly alters the level of cholecystokinin immunoreactivity within cells of three interconnected sexually dimorphic forebrain nuclei in the rat. Proc. Natl. Acad. Sci. U.S.A. 84:2087-2091.

Simerly, R.B., and L.W. Swanson (1988) Projections of the medial preoptic nucleus: a Phaseolus vulgaris leucoagglutinin anterograde tract-tracing study in the rat. J. Comp. Neurol. 270:209-242.

Simerly, R.B., C. Chang, M. Muramatsu, and L.W. Swanson (1990) Distribution of androgen and estrogen receptor mRNA-containing cells in the rat brain: an in situ hybridization study. J. Comp. Neurol. 294:76-95.

Swann, J.M., and S.W. Newman (1987) Effects of castration and testosterone treatment on substance $P$ levels within the vomeronasal pathway of the male golden hamster. Soc. Neurosci. 13:1576.

Swanson, L.W. (1976) An autoradiographic study of the efferent connections of the preoptic region in the rat. J. Comp. Neurol. 167:227-256. 
Swanson, L.W., and W.M. Cowan (1976) The connections of the septal region. J. Comp. Neurol. 186:621-656.

Swanson, L.W. (1987) The Hypothalamus. In A. Bjorkland, T, Hokfelt and L.W. Swanson (eds): Handbook of Chemical Neuroanatomy, Vol. 5, Integrated Systems of the CNS, Part I. New York: Elsevier, pp. 1-104.

Switzer, R.C., J. De Olmos, and L. Heimer (1985) Olfactory system. In G Paxinos (ed): The Rat Nervous System. New York: Academic Press. pp. $1-36$.

Weller, K.L., and D.A. Smith (1982) Afferent connections to the bed nucleus of the stria terminalis. Brain Res. 232:255-270.

Winans, S.S., and J.B. Powers (1977) Olfactory and vomeronasal deafferen- tation of male hamsters: Histological and behavioral analyses. Brain Res. 126:325-344

Winans, S.S., M.N. Lehman, and J.B. Powers (1982) Vomeronasal and olfactory CNS pathways which control male hamster mating behavior. In W. Breipohl (ed): Olfaction and Endocrine Regulation. London: IRI Press Limited.

Zaborsky, L., G.F. Alheid, M.C. Beifeld, L.E. Eiden, L. Heimer, and M. Palkovits (1985) Cholecystokinin innervation of the ventral striatum: A morphological and radioimmunological study. Neuroscience 14:427453. 